\title{
Graft copolymerized chitosan-present status and applications
}

\author{
R. Jayakumar ${ }^{\mathrm{a}, \mathrm{b}}$, M. Prabaharan ${ }^{\mathrm{a}, \mathrm{b}}$, R.L. Reis ${ }^{\mathrm{a}, \mathrm{b}}$, J.F. Mano ${ }^{\mathrm{a}, \mathrm{b}, *}$ \\ a3B's Research Group-Biomaterials, Biodegradables and Biomimetics, University of Minho, Campus of Gualtar, 4710-057 Braga, Portugal \\ ${ }^{\mathrm{b}}$ Department of Polymer Engineering, University of Minho, Campus of Azurem, 4800-058 Guimarães, Portugal \\ Received 4 January 2005; revised 30 May 2005; accepted 20 July 2005 \\ Available online 26 September 2005
}

\begin{abstract}
Chitosan is a natural based polymer obtained by alkaline deacetylation of chitin, exhibiting excellent biological properties such as biodegradation in the human body, and immunological, antibacterial, and wound-healing activity. Chitosan has also been found to be a good candidate as a support material for gene delivery, cell culture and tissue engineering. However, practical use of chitosan has been mainly confined to the unmodified forms. For a breakthrough in utilization, graft copolymerization onto chitosan will be a key point, which will introduce desired properties and enlarge the field of the potential applications of chitosan by choosing various types of side chains. This article reviews the various methods such as free radical, radiation, enzymatic and cationic graft copolymerization onto chitosan, the factors influencing on the grafting parameters such as grafting percentage and grafting efficiency, and the properties of grafted chitosan. This review also screens the current applications of graft copolymerized chitosans in the field of drug delivery, tissue engineering, antibacterial, biomedical, metal adsorption and dye removal.
\end{abstract}

(C) 2005 Published by Elsevier Ltd.

Keywords: Chitosan; Grafting; Grafting efficiency; Drug delivery; Biomedical applications

\section{Introduction}

Chitosan is a partially deacetylated polymer of acetyl glucosamine obtained after alkaline deacetylation of the chitin. It displays interesting properties such as biocompatibility, biodegradability (Ravi kumar, 2000; Ravi Kumar et al., 2004; Felt, Buri, \& Gurny, 1998; Hirano et al., 1989; Sanford, 1989) and its degradation products are non-toxic, non-immunogenic and non-carcinogenic (Muzzarelli, 1997; Felt, Buri, \& Gurny, 1998; Bersch et al., 1995). Therefore, chitosan has prospective applications in many fields such as biomedicine, waste water treatment, functional membranes and flocculation. However, chitosan can only soluble in few dilute acid solutions, which limits its wide applications. Recently, there has been a growing interest in chemical modification of chitosan to improve its solubility and widen its applications (Sugimoto, Morimoto, \& Sashiwa, 1998; Kurita et al., 1998; Sashiwa \& Shigemasa, 1999; Terada, Morimoto, Saimoto, Okamato, Minami and Shigemasa,

\footnotetext{
* Corresponding author. Tel.: +351 253 510330; fax: + 351253510339 .

E-mail address: jmano@dep.uminho.pt (J.F. Mano).
}

0144-8617/\$ - see front matter (C) 2005 Published by Elsevier Ltd. doi:10.1016/j.carbpol.2005.07.017
1999; Alexandrova, Obukhova, Dominina, \& Topchiev, 1999; Sridhari \& Dutta, 2000; Heras, Rodriguez, \& Ramos, 2001). Among various methods, graft copolymerization is most attractive because it is a useful technique for modifying the chemical and physical properties of natural polymers. Chitosan bears two types of reactive groups that can be grafted. First, the free amino groups on deacetylated units and secondly, the hydroxyl groups on the $\mathrm{C}_{3}$ and $\mathrm{C}_{6}$ carbons on acetylated or deacetylated units. Grafting of chitosan allows the formation of functional derivatives by covalent binding of a molecule, the graft, onto the chitosan backbone. Recently researchers have also shown that after primary deviation followed by graft modification; chitosan would obtain much improved water solubility and bioactivities such as antibacterial and antioxidant properties (Xie, $\mathrm{Xu}$, Wang, \& Lu, 2001, 2002). Grafting chitosan is a common way to improve chitosan properties such as increasing chelating (Yang \& Yuan, 2001) or complexation properties (Chen \& Wang, 2001), bacteriostatic effect (Jung et al., 1999) or enhancing adsorption properties (Kotze, Lueßen, De Leeuw, De Boer, Verhoef and Junginger, 1997; Thanou, Verhoef, \& Junginger, 2001). Although the grafting of chitosan modifies its properties, it is possible to maintain some interesting characteristics such as 
mucoadhesivity (Hoffmann et al., 1997), biocompatibility (Tasker, Connell, Ross, \& Elson, 1998; Ono, Saito, Yura, \& Ishikawa, 2000) and biodegradability (Singh \& Ray, 1998). Many investigations have been carried out on the graft copolymerization of chitosan in view of preparing polysaccharide-based advanced materials with unique bioactivities and thus widening their applications in biomedicine and environmental fields.

A few review articles on the potential applications of chitosan for pharmaceutical, veterinary medicine, biomedical and environmental field have already been reported (Suh \& Matthew, 2000; Ravi kumar, 2000; Ravi Kumar et al., 2004; Berger, Reist, Mayer, Belt, \& Gurny, 2004; Senel \& McClure, 2004; Verma, Deshpande, \& Kennedy, 2004; Guibal, 2004; Kurita, 2001, Prabaharan \& Mano, 2005). However, there is no review available on the graft copolymerization of chitosan and its applications, despites the considerable amount of works have been published in this field. This review intends to systematize related issues that includes: various methods of chitosan grafting; the effects of reaction variables such as type and concentration of initiator, monomer concentration, reaction temperature and time on the grafting efficiency; and the physicochemical properties of grafted chitosan. Moreover, the potential applications of grafted chitosan in the various fields such as drug delivery, biomedical, tissue engineering and environmental is also discussed. Finally, an attempt is made to discuss some of the current applications and future prospects of grafted chitosan.

\section{Methods of graft copolymerization}

Chemical modifications will open ways to various utilizations of polysaccharides. Of possible modifications, graft copolymerization is anticipated to be quit promising for developing sophisticated functions; it would enable a wide variety of molecular designs to afford novel types of tailored hybrid materials composed of natural polysaccharides and synthetic polymers (Yoshikawa, Takayama, \& Tsubokawa, 1998; Pedram, Lagos, Campos, \& Retuert, 1992; Retuert, \& Yazdani-Pedram, 1993; Pedram, Lagos, Retuert, Guerrero, \& Riquelme, 1995). Graft copolymerization of synthetic polymers onto chitosan can introduce desired properties and enlarge the field of the potential applications of them by choosing various types of side chains. In recent years, a number of initiator systems such as, ammonium persulfate (APS), potassium persulfate (PPS), ceric ammonium nitrate (CAN), thiocarbonationpotassium bromate (TCPB), potassium diperiodatocuprate (III) (PDC), 2, 2' -azobisisobutyronitrile (AIBN) and ferrous ammonium sulfate (FAS) have been developed to initiate grafting copolymerization (Caner, Hasipoglu, Yilmaz, \& Yilmaz, 1998; Don, King, \& Chiu, 2002; Kim, Cho, Lee, \& Kim, 2000; Pedram \& Retuert, 1996; Pedram, Retuert, \& Quijada, 2000; Blair, Guthrie, Law, \&
Turkington, 1987). It is also reported that graft copolymerization is initiated by $\gamma$-irradiation and enzymes. The grafting parameters such as grafting percentage and grafting efficiency are greatly influenced by type and concentration of initiator, monomer concentration, reaction temperature and time. The properties of the resulting graft copolymers are widely controlled by the characteristics of the side chains, including molecular structure, length, and number. Till today, a number of research works have been done to study the effects of these variables on the grafting parameters and the properties of grafted chitosan polymers (Sun et al., 2003; Xie et al., 2002; Don, King, \& Chiu, 2002; Kim, Cho, Lee, \& Kim, 2000; Pedram \& Retuert, 1996; Pedram, Retuert, \& Quijada, 2000; Blair, Guthrie, Law, \& Turkington, 1987).

\subsection{Grafting initiated by free radicals}

Graft copolymerization of vinyl monomers onto chitosan using free radical initiation has attracted the interest of many scientists in the last two decades. This technique enables the production of new polymer materials with desired properties. Sun et al. (2003) prepared the carboxymethyl chitosangrafted-MAA by using APS as an initiator in an aqueous solution. The effects of APS, MAA, reaction temperature and time on graft copolymerization were studied by determining the grafting percentage and grafting efficiency. It was found that the reaction conditions such as initiator concentration, monomer concentration, reaction temperature and time had great influence on grafting copolymerization. After grafting, the chitosan derivatives had much improved water solubility. Similarly, Xie et al. (2002) prepared hydroxypropyl chitosan-grafted-MAA by using APS initiator (Fig. 1). Here also, it was reported that the reaction variables play an important role in the grafting copolymerization. The graft copolymerization of maleic acid sodium (MAS) onto carboxymethyl chitosan and hydroxypropyl chitosan using APS initiator was reported (Sun, Xie, \& Xu, 2004). The antioxidant activity of these derivatives was evaluated as superoxide anion scavengers by chemiluminescence technology. Compared with chitosan, the graft chitosan derivatives were found to be improved scavenging ability against superoxide anion. Graft chitosan derivatives with hydroxypropyl groups had relatively higher superoxied anion scavenging ability owing to the incorporation of hydroxyl groups. The effect of monomer concentration and temperature on percent grafting of poly (4-vinylpyridine) on to chitosan was reported (Caner, Hasipoglu, Yilmaz, \& Yilmaz, 1998). The percent grafting was observed to increase with the amount of monomer, showing a tendency to level off at a poly (4-vinylpyridine) concentration of $0.53 \mathrm{~mol} / \mathrm{L}$. The percent grafting was increased up to $70{ }^{\circ} \mathrm{C}$ and then decreased at $80^{\circ} \mathrm{C}$. $\mathrm{N}$-Acylation of chitosan with maleic anhydride furnishes carbon-carbon double bonds, which are available for subsequent polymerization. The copolymerization of 


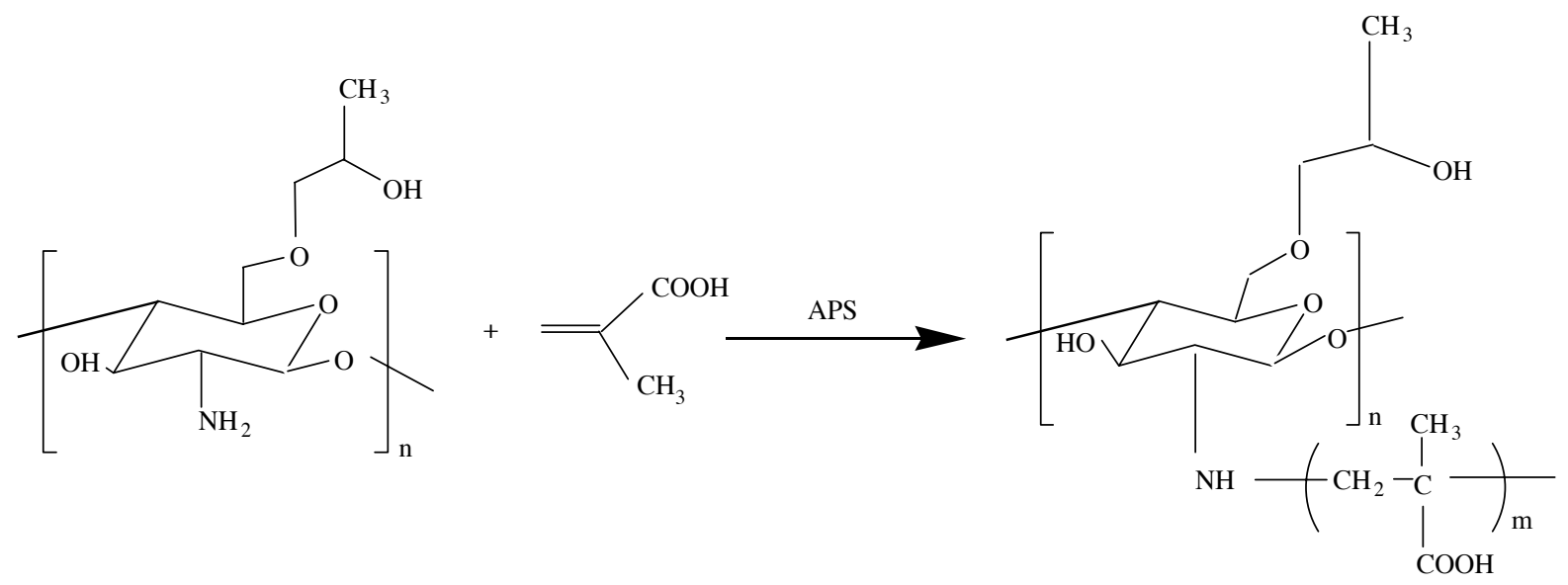

Fig. 1. Graft copolymerization of methacrylic acid on hydroxypropyl chitosan.

the derivative with acrylamide in water in the presence of APS has given three-dimensional cross-linked products. The resulting copolymers swelled highly in water with a volume increase of 20-150 times (Berkovich, Tsyurupa, \& Davankov, 1983). Poly (3-hydroxy-butylate) could also be introduced into chitosan by $N$-acylation, and the resulting copolymer was found to be partial water solubility and formed an opaque aqueous solution (Yalpani, Marchessault, Morin, \& Monasterious, 1991). Due to these properties, this polymer may have good film-forming capacity.

Polyaniline is an interesting air-stable organic conductive material. The polymerization of aniline in the presence of chitosan has resulted in a graft copolymer, which is soluble in a slightly acidic aqueous solution and forms selfsupporting materials, including thick films and fibers, which are conductive when protonically doped. The reaction of chitosan in aqueous acetic acid solution with aniline in the presence of APS enables the introduction of polyaniline side chains at the amino groups (Yang et al., 1989) (Fig. 2). Chitosan-grafted-polyaniline was fabricated into films and fibres, but the properties varied according to the ratio of the amino group to aniline in the grafting reaction. With the ratio of $1: 1$ to $1: 5$, the products were sturdy and flexible, while those with a 1:6 to 1:10 ratios were brittle. Optical microscopic observations indicated that the products prepared at a ratio below 1:5 were homogeneous, but those above 1:6 had crystalline regions. The graft copolymers were deep blue and became dark green when treated with hydrochloric acid, and protonic doping raised the conductivity from less than $10^{-7}$ to $10^{-2} \mathrm{~S} / \mathrm{cm}$ (Yang et al., 1989).

Graft copolymerization of vinyl monomers onto chitosan is also carried out using redox initiator systems, such as CAN and PPS. These systems have been used to produce free radical sites on many kinds of polymers. Poly(vinyl acetate) (PVAc) is known as a leathery and water-resistant polymer, which may improve the properties of chitosan material and hence the graft polymerization of vinyl acetate onto the chitosan at $60^{\circ} \mathrm{C}$ by using $\mathrm{CAN}$ as an initiator was reported (Don, King, \& Chiu, 2002). The reaction mechanism is the following:

\section{Initiation}

(1) Direct oxidation

$$
\begin{aligned}
& \mathrm{Cs}+\mathrm{Ce}^{4+} \rightarrow \mathrm{Cs}^{\cdot}+\mathrm{Ce}^{3+}+\mathrm{H}^{+} \\
& \mathrm{Cs}^{\cdot}+\mathrm{M} \rightarrow \mathrm{CsM}
\end{aligned}
$$

(2) Formation of complex

$$
\begin{aligned}
& \mathrm{Cs}+\mathrm{Ce}^{4+} \leftrightarrow \text { complex } \\
& \text { complex } \rightarrow \mathrm{Cs}^{\cdot}+\mathrm{Ce}^{3+}+\mathrm{H}^{-} \\
& \mathrm{Cs}+\mathrm{M} \rightarrow \mathrm{CsM}
\end{aligned}
$$

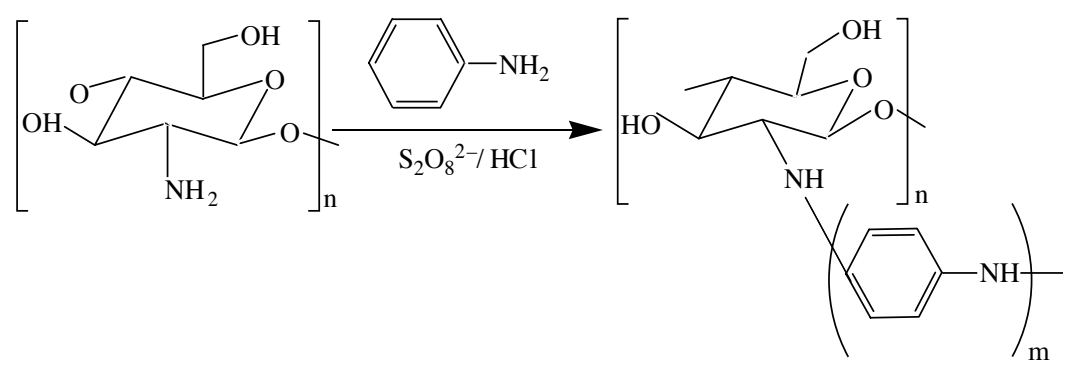

Fig. 2. Graft copolymerization of polyaniline on chitosan. 
Where $\mathrm{Cs}$ is a chitosan chain; $\mathrm{Ce}^{4+}$ and $\mathrm{Ce}^{3+}$, ceric and cerous ions, respectively; $\mathrm{Cs}^{\circ}$, a chitosan chain radical; and $\mathrm{M}$, the vinyl acetate monomer.

2. Propagation

$$
\begin{aligned}
& \mathrm{CsM}+\mathrm{M} \rightarrow \mathrm{CsM}_{2} \\
& \mathrm{CsM}_{x}^{\cdot}+\mathrm{M} \rightarrow \mathrm{CsM}_{x+1}^{\cdot}
\end{aligned}
$$

Where $\mathrm{CsM}_{x}$ is a propagating PVAc chain grafted onto the chitosan.

3. Termination

$$
\begin{aligned}
& \mathrm{CsM}_{x}^{+}+\mathrm{P} \rightarrow \mathrm{CsM}_{x}+\mathrm{P} \\
& \mathrm{CsM}_{x}+\mathrm{P} \rightarrow \mathrm{CsM}_{x} \mathrm{P}
\end{aligned}
$$

Where $\mathrm{P}^{\prime}$ indicates all the propagating polymer chains, $\mathrm{P}^{\cdot}=\mathrm{CsM}_{x}+\mathrm{M}_{x}$, and $\mathrm{M}_{x}$ is the PVAc chain radical; $\mathrm{CsM}_{x}$, $\mathrm{CsM}_{x} \mathrm{P}$, and $\mathrm{P}$ are all dead polymers.

4. Chain transfer

$$
\begin{aligned}
& \mathrm{CsM}_{x}+\mathrm{Ce}^{4+} \rightarrow \mathrm{CsM}_{x}+\mathrm{Ce}^{3+}+\mathrm{H}^{+} \\
& \mathrm{CsM}_{x}^{+}+\mathrm{M} \rightarrow \mathrm{CsM}_{x}+\mathrm{M} \\
& \mathrm{CsM}_{x}^{\cdot}+\mathrm{P} \rightarrow \mathrm{CsM}_{x}+\mathrm{P}
\end{aligned}
$$

The monomer conversion was found to be between 70 and $80 \%$ after $2 \mathrm{~h}$ of reaction at $60{ }^{\circ} \mathrm{C}$. The grafting efficiency increased with increasing amount of chitosan. The experimental results indicated that the chitosan molecules not only took part in the graft copolymerization but also used as a surfactant, providing the stability of the dispersed particles. The DSC and TGA results showed that the samples underwent oxidative degradation by the residual CAN at temperatures above $200{ }^{\circ} \mathrm{C}$. The experimental results also showed that the incorporation of PVAc to the chitosan chains increased the toughness and decreased the water absorption of chitosan.

The grafting of zwitterionic monomer, $N, N$-dimethyl- $N$ methacryloxyethyl- $N$-(3-sulfopropyl) ammonium, onto chitosan using CAN as redox initiator in acetic acid solution under nitrogen atmosphere was investigated (Zhang et al., 2003). The grafting efficiency was studied by varying the temperature, the time as well as the concentration of initiator and monomer. In this study, 50\% grafting was obtained under optimum condition. The TGA studies showed that the grafted chitosan degrades slowly than chitosan. Similar study has been done to prepare thermoand $\mathrm{pH}$ sensitive polymers by graft copolymerization of poly ( $N$-isopropylacrylamide) onto chitosan by using CAN initiator (Kim, Cho, Lee, \& Kim, 2000). The graft copolymer was characterized by FTIR, TGA, X-ray and solubility studies. It was found that the percentage of grafting and grafting efficiency depends upon poly ( $N$-isopropylacrylamide) concentration. The resulted chitosan-grafted-poly( $N$-isopropylacrylamide) exhibited swelling/deswelling changes in response to external stimuli such as $\mathrm{pH}$ and temperature, and could be useful as novel modulation systems in biomedical fields. The effect of reaction conditions on the rate of poly(acrylonitrile) grafting onto chitosan under inert atmosphere in presence of CAN initiator was studied (Pourjavadi, Mahdavina, Mehr, \& Omidian, 2003). The following optimum conditions for grafting copolymerization were determined: chitosan amount $0.20 \mathrm{~g}$; acetic acid $2 \% \mathrm{w} / \mathrm{w}$; reaction temperature $50{ }^{\circ} \mathrm{C}$; CAN concentration $0.006 \mathrm{M}$; time $2 \mathrm{~h}$. In this study, the empirical polymerization rate $(R \mathrm{p})$ showed a first order dependency on the monomer concentration and a half-order dependency on their initiator concentration. It was also found that the concentration of the CAN initiator had more influence on the polymerization rate than the concentration of poly(acrylonitrile) monomer. Graft copolymerization of 2-Hydroxy ethyl methacrylate (HEMA) on to chitosan was studied using CAN as the initiator (Radhakumary, Divya, Nair, Mathew, \& Nair, 2003). Optimization of the grafting was studied by varying the reaction time and monomer concentration. Under controlled conditions, up to $685 \%$ grafting with a grafting yield of $92.4 \%$ was achieved. Grafting caused a marginal decrease in the mechanical strength in the dry conditions and a significant decrease under wet conditions for the resultant polymer. The products showed significantly improved swelling at $\mathrm{pH}$ 7.4 and $\mathrm{pH} 1.98$ compared to the original chitosan. Grafted polymer showed enhanced glass transition and decomposition temperature. The grafting also resulted in improved hydrophilicity as is evident from the contact angle studies of the films. CAN is also reported as a suitable initiator for grafting polyacrylamide, poly(acrylic acid), poly(4-vinylpyridine) onto chitosan (Caner, Hasipoglu, Yilmaz, \& Yilmaz, 1998).

Modification of chitosan by grafting of vinyl pyrrolidone was carried out in homogeneous phase using PPS as redox initiator. The effect of the reaction variables on the extent of grafting was studied systematically (Pedram \& Retuert, 1996). It was observed that the solubility of chitosan was markedly reduced after grafting with vinyl pyrrolidone. The grafted product was found to be insoluble in common organic solvents as well in dilute organic and inorganic acids, evidencing an enhanced hydrophobic character as compared to ungrafted chitosan. However, the solubility of the grafted chitosan after adsorption of copper ions changed substantially, becoming completely soluble in dilute hydrochloric acid. This was attributed to the effect of complex formation produced by coordination of amino groups of chitosan with copper ions. Prasanth \& Tharanathan (2003) investigated the graft copolymerization of acrylonitrile and methylmethacrylate onto chitosan using PPS as an initiator. The grafting was confirmed by IR and CP-MAS ${ }^{13} \mathrm{C}$ NMR. In this study, it was observed that the degree of substitution varied from 2 to 50 , by changing the monomer concentration from 40 to $180 \mathrm{mM}$. The maximum 
acrylonitrile grafting efficiency was obtained at $120 \mathrm{mM}$ acrylonitrile and $0.74 \mathrm{mM}$ persulfate at $65^{\circ} \mathrm{C}$ for $2 \mathrm{~h}$ under nitrogen atmosphere for $1 \%$ chitosan solution. The maximum polymethylmethacrylate substitution onto chitosan was obtained at $140 \mathrm{mM}$ methyl methacrylate at $75^{\circ} \mathrm{C}$. The X-ray diffraction studies showed that there are changes in the crystalline pattern of grafted chitosan. The DSC thermogram showed a decomposition peak for chitosangrafted-polyacrylonitrile at about $255^{\circ} \mathrm{C}$ and a melting peak for chitosan-grafted-polymethylmethacrylate at about $400{ }^{\circ} \mathrm{C}$. The scanning electron micrographs of native chitosan showed a fibrous structure, whereas chitosangrafted-polyacrylonitrile and chitosan-grafted-polymethylmethacrylate showed a flaky and beads-like structure, respectively. The graft copolymers could be thermo pressed to thin membrane films.

Chitosan was modified with poly(acrylic acid), a wellknown hydrogel forming polymer, using a grafting reaction in a homogeneous phase (Pedram, Retuert, \& Quijada, 2000). The grafting was carried out in presence of PPS and FAS as the combined redox initiator system. The efficiency of grafting was found to depend on monomer, initiator, and ferrous ion concentrations, as well as on the reaction time and temperature. It was observed that the level of grafting could be controlled to some extend by varying the amount of ferrous ion as a co-catalyst in the reaction. The maximum efficiency of grafting attained in this work $(52 \%)$ is rather high but it is comparable with values reported recently in the literature for the grafting of vinyl monomers onto polysaccharides. This result revealed that in homogeneous systems the grafting reactions takes place not only on the surface but also in the molecules of the whole substrate.

A grafted material based on chitosan and 2-Acrylamide2-methyl propanesulfonic acid (AMPS) has been prepared in homogenous solution using PPS as a redox initiator (Najjar, Yunus, Ahmad, \& Rahman, 2000). The effects of the reaction temperature and chitosan-PPS contact time as well as concentrations of AMPS, PPS, and acetic acid on grafting yield were investigated. The percentage of grafting was found to be increased with the increasing of the AMPS concentration. The reaction variables were optimized in order to obtain the maximum grafting percentage. The optimum conditions were reported as follows: reaction temperature, $50{ }^{\circ} \mathrm{C}$; chitosan-PPS mixing period, $5 \mathrm{~min}$; amount of PPS, $0.37 \mathrm{mmol}$; amount of AMPS, $28.96 \mathrm{mmol}$, acetic acid concentration, $1 \%$ v/v. Tahlawy and Hudson (2001) have discussed the effects of the reaction conditions and temperature on the grafting efficiency of 2-hydroxyethylmethacrylate (HEMA) onto chitosan in presence of redox initiator, i.e. TCPB. Here, the total conversion of HEMA monomer was found to be up to $75 \%$. The maximum graft yield (38\%) was attained at the optimum reaction conditions. The resulted material was found to increase the hydrophilicity and therefore may be used as textile finishes enhancing the hydrophilicity of synthetic fibers.
A novel redox system, PDC [Cu (III)-chitosan], was employed to initiate the graft copolymerization of methyl acrylate onto chitosan in alkali aqueous solution (Liu et al., 2003). In this work, $\mathrm{Cu}$ (III) was employed as an oxidant and chitosan as a reductant in the redox system used to initiate the grafting reaction. The result showed that there is a high grafting efficiency and percentage while using PDC as an initiator. Since the activation energy of the reaction employing $\mathrm{Cu}$ (III)-chitosan as an initiator is low, the graft copolymerization is carried out at a mild temperature of $35^{\circ} \mathrm{C}$ and in alkali aqueous medium, which makes it superior to other initiators. Graft copolymerization onto chitosan has also been attempted by using AIBN initiator. Some vinyl monomers such as acrylonitrile, methyl methacrylate, methyl acrylate, and vinyl acetate were grafted onto chitosan with AIBN in aqueous acetic acid solutions or in aqueous suspensions. Here, the grafting percentages were generally found to be low (Blair, Guthrie, Law, \& Turkington, 1987). Fenton's reagent $\left(\mathrm{Fe}^{2+} / \mathrm{H}_{2} \mathrm{O}_{2}\right)$ is also used as a redox initiator for grafting methyl methacrylate onto chitosan. The grafting percentage and efficiency were found to be 72 and $66.5 \%$, respectively (Lagos \& Reyes, 1988). Although chitosan is an effective flocculating agent only in acidic media, the derivatives having side chain carboxyl groups showed zwitterionic characteristics with high flocculation abilities in both acidic and basic media.

\subsection{Grafting by using radiation}

Recently, a great interest has been made to graft natural polymers using radiation method. Grafting of polystyrene onto chitin and chitosan using ${ }^{60} \mathrm{Co} \gamma$-irradiation at room temperature was investigated (Pengfei, Maolin, \& Jilan, 2001; Shigeno et al., 1982). The grafting yield was controlled by changing the grafting conditions. The effect of various conditions such as adsorbed dose, solvent and oxygen on grafting was investigated. It was found that the grafting yield increased with the increase in adsorbed dose. Singh and Roy (1997) have also reported the radiation grafting of chitosan with $N, N^{\prime}$-dimethylaminiethylmethacrylate (DMAEMA). The following parameters such as, solvent composition, monomer concentration, radiation dose rate, and total doce/time were found to be affecting the rate of grafting and homo polymerization. In this study, it was found that a desired level of grafting of DMAEMA onto chitosan films was achieved by appropriate selection of grafting conditions. The degree of swelling, crystallinity, and tensile strength decreased by 51, 43, and 37\%, respectively, at a 54\% graft level of DMAEMA, whereas modified films showed improved thermal stability.

Yu et al. (2003) have reported the graft copolymerization of butyl acrylate onto chitosan by using $\gamma$-irradiation. In this study, increasing grafting percentage was observed when the monomer concentration and total dose were increased or when the chitosan concentration and reaction temperature 
were decreased. Under lower dose rates, the grafting percentage has no significant change, whereas, above $35 \mathrm{~Gy} / \mathrm{min}$ (dose rate) the grafting percentage exhibits a sharp decrease. Compared with pure chitosan film, the chitosan graft poly(butyl acrylate) films have enhanced hydrophobic and impact strength. Similar work has also been reported for grafting poly(hydroxyethyl methacrylate) with chitosan in presence of UV light (Ng, Guthrie, Juan, \& Zhao, 2001). Here, the sulfite oxidase enzyme was covalently immobilized onto the matrix of grafted polymer. After the completion of photo-induced polymerization reaction, $P$-benzoquinone (an electron transfer mediator) was coupled onto the polymer network for activation of the chitosan- poly(hydroxyethyl methacrylate) copolymer. This study demonstrated the feasibility of using chitosan in electrochemical biosensor fabrication ( $\mathrm{Ng}$, Guthrie, Juan, \& Zhao, 2001). Singh et al. (2005) grafted polyacrylonitrile onto chitosan using microwave irradiation technique under homogeneous conditions. They have obtained 170\% grafting yield within $1.5 \mathrm{~min}$. The effects of reaction variables as monomer or chitosan concentration, microwave power, and exposure time on the graft copolymerization were studied. The grafting was found to increase with an increase in the initial concentration of monomer. Grafting was also found to increase up to $80 \%$ microwave power and there after decrease. The grafted chitosan showed a good solubility at higher $\mathrm{pH}$ than chitosan.

\subsection{Enzymatic grafting}

There are several potential advantages for the use of enzymes in polymer synthesis and modification (Dordick, 1992; Kaplan et al., 1998). With respect to health and safety, enzymes offer the potential of eliminating the hazards associated with reactive reagents. A potential environmental benefit for using enzymes is that their selectivity may be exploited to eliminate the need for waste full protection and deprotection steps. Finally, enzymes specificity may offer the potential for precisely modifying macromolecular structure to better control polymer function (Kumar et al., 1999; Yamada, Chen, Kumar, Vesnovsky, Topoleski and Payne, 2000). For instance, enzymatic modification can

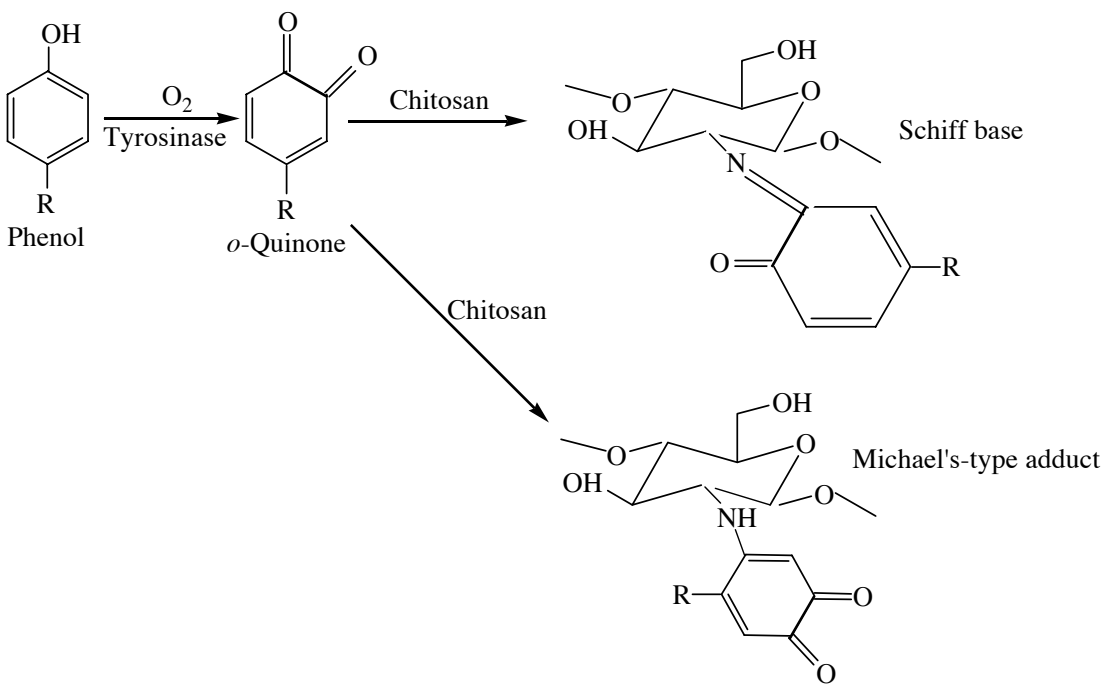<smiles>O=C(/C=C/c1ccc(O)c(O)c1)OC1CC(O)(C(=O)O)CC(O)C1O</smiles><smiles>CCOc1ccc(O)cc1</smiles>

Fig. 3. Enzymatic grafting of chitosan with phenol and tyrosinase. 
yield chitosan derivatives with unique $\mathrm{pH}$-sensitive watersolubility and adhesive properties. Kumar, Smith and Payne (1999) reported enzymatic grafting of phenolic compounds onto chitosan to confer water solubility under basic conditions (Fig. 3). Tyrosinase converts a wide range of phenolic substrates into electrophilic $o$-quinones. In slightly

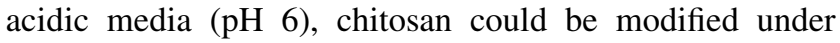
homogeneous conditions with the natural product chlorogenic acid. The modified chitosan was soluble under both acid and basic conditions, even when the degree of modification was low. The chemistry of quinones, however, remains poorly characterized because of its complexity, quinones can undergo two different reactions to yield either Shiff bases or Michael type adducts. Since it is possible for quinones to undergo either or both type of reactions with amines, as well as oligomer forming reactions with other quinones, it is common for reactions between quinones and amines to yield complex mixtures of products.

The feasibility of using tyrosinase as a catalyst for grafting hexyloxyphenol onto the chitosan was investigated (Chen et al., 2000). The method employs tyrosinase to convert the phenol into a reactive o-quinone, which undergoes subsequent non-enzymatic reaction with chitosan under homogeneous conditions (Fig. 3). The spectral studies showed that hexyloxyphenol-modified chitosans have dramatically altered the physicochemical behavior. On the basis of contact angle measurements, the heterogeneous modification of a chitosan film was found to produce a hydrophobic surface due to the substituent. While, homogeneously modified chitosan exhibited rheological properties characteristic of associating water-soluble polymers. In order to confer the functional properties of chitosan, horseradish peroxidase was also used as a catalyst in the grafting reaction. Using this enzyme, it was possible to graft the phenolic substrate dodecyl gallate onto the chitosan (Vachoud, Chen, Payne, \& Duhalt, 2001). From the biochemically relevant quinones studied so far, it would seem possible to prepare materials of medical interest. For instance, menadione, a synthetic naphthoquinone derivative having the physiological properties of vitamin $\mathrm{K}$ is particularly prone to rapid reaction with chitosan, greatly modifying its spectral characteristics and increasing the surface hydrophobicity of treated chitosan films (Muzzarelli, \& Muzzarelli, 2002). Research under way will provide information on the biological properties of these enzymatically modified chitosans.

\subsection{Cationic graft polymerization}

The grafting reaction onto chitosan is also performed by using living cationic polymerization. Yoshikawa et al. (1998) have grafted the chitosan with living poly(isobutylvinyl ether) and poly(2-methyl-2-oxazoline) cation with controlled molecular weight distribution. In this study, the effect of molecular weight of living polymer cation on the mole number of grafted polymer was studied. The mole number of grafted polymer chains was found to decrease with the increasing molecular weight of living polymer cation because of the steric hindrance of functional groups of chitosan with the increasing molecular weight of living polymer. The viscosity of the resulting polymer was found to have increased with the increasing percentage of grafting. The grafted polymer was also found to be soluble in water.

\section{Applications}

\subsection{Drug delivery systems}

Drug delivery has been a very active area, especially for chitosan as a carrier for various active agents including drugs and biologics due to its physicochemical and biological properties. It is extremely important that chitosan be hydro-soluble and positively charged. These properties enable it to interact with negatively charged polymers, macromolecules and polyanions on contact in an aqueous environment. It has the special feature of adhering to mucosal surfaces, a fact that makes it a useful polymer for mucosal drug delivery (Lehr et al., 1992; Artursson et al., 1994; Lueben, Leeuw, Langemeyer, Boer, Verhoef and Junginger, 1996; Illum et al., 1994). Chitosan has interesting biopharmaceutical characteristics such as $\mathrm{pH}$ sensitivity, biocompatibility and low toxicity (Hirano et al., 1989; Bersch et al., 1995). Moreover, chitosan is metabolised by certain human enzymes, especially lysozyme, and is considered as biodegradable (Muzzarelli, 1997). Due to these favorable properties, the interest in chitosan and its derivatives as excipients in drug delivery has been increased in recent years.

Acrylic acid grafts of chitosan as possible means of creating hydrophilic and mucoadhesive polymers, has been reported recently (Shanthi \& Rao, 2001; Ahn et al., 2001; Hu et al., 2002; Sun et al., 2003). Polymerization of acrylic acid onto chitosan can lead to inter- and intra-molecular linkages between carboxyl groups of poly(acrylic acid) and positively charged amino group of chitosan. Chitosangrafted-poly(acrylic acid) particles have been proposed as hydrophilic drug carriers for hydrophilic drugs and sensitive proteins. Shantha et al. (1995) have reported the graft copolymers of chitosan with acrylic and methacrylic acids by using ceric ion initiator. The graft copolymers were subsequently utilized for the preparation of functionalized chitosan beads by a polymer dispersion technique. Sulphadiazine was entrapped in the microspheres and the in vitro drug release profiles were established both in simulated gastric and intestinal fluids. The overall drug release data indicated that the incorporated sulphadiazine released faster by 5 days $(99.6 \%)$ in the gastric fluid as compared to the intestinal fluid, which took 6 days for the release of $98 \%$ of sulphadiazine. These results are indicated that the grafted chitosans will have great influence on the release pattern of the incorporated drug. 
Kumbar et al. (2003) have used the microspheres of polyacrylamide-grafted-chitosan cross-linked with glutaraldehyde to encapsulate indomethacin (IM), a nonsteriodal anti-inflammatory drug used in the treatment of arthrthitis. The microspheres with a mean particle size of $525 \mu \mathrm{m}$ were produced by the water/oil emulsion technique and encapsulation of IM was carried out before cross-linking matrix. Microspheres were characterized for drug-entrapment efficiency, particle size, and water transport into the polymer matrix, as well as for drug release kinetics. Dynamic swelling experiments suggested that, with an increase in cross-linking, the transport mechanism changed from Fickian to non-Fickian. The release of IM depends upon the cross-linking of the network and also on the amount of drug loading. The initial release of IM from these microspheres is due to the polymer chain relaxation process, but at longer times, the release occurs from the fully swollen polymer and is controlled mainly by the molecular diffusion phenomenon. The grafting of acrylamide onto a chitosan using $\mathrm{K}_{2} \mathrm{~S}_{2} \mathrm{O}_{8}$ induced free-radical polymerization was also carried out (Kumbar \& Aminabhavi, 2003). Microspheres of grafted chitosan cross-linked with glutaraldehyde were prepared to encapsulate nifidifine (NFD), a calcium channel blocker and an antihypertensive drug. It is found that the release of NFD depended on the extent of cross-linking and the amount of drug loading. In all the formulations, drug release was delayed for more than $10 \mathrm{~h}$. The release of NFD from the microspheres followed zero order kinetics.

Deoxycholic acid, which is the main component of bile acids, was used to modify chitosan hydrophobically and to obtain self-assembling macromolecules for non-viral gene delivery system. The self-aggregate-DNA complex from deoxycholic acid-modified chitosan (Fig. 4) was shown to enhance the transfection efficiency over monkey kidney cells (Kim, Kim, \& Park, 2001). Chitosan containing 5.1 deoxycholic acid groups per 100 anhydroglucose units was synthesized by a 1-ethyl-3-(3-dimethyamino propyl)

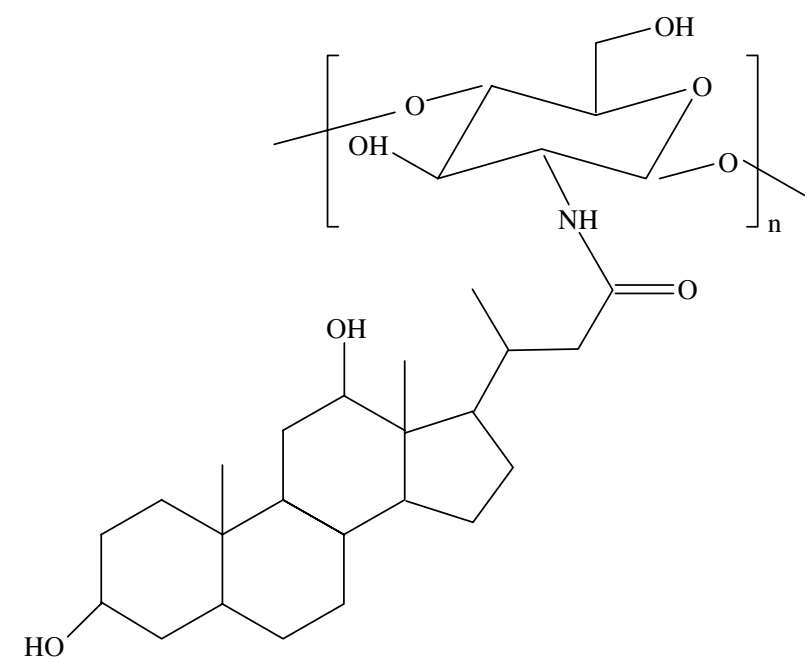

Fig. 4. Deoxycholic acid modified chitosan. carbodiimide (EDC) mediated coupling reaction. The feasibility of chitosan self-aggregates for the transfection of genetic material in mammalian cells was also investigated. Self-aggregates can form charge complexes when mixed with plasmid DNA. These self-aggregate DNA complexes are considered to be useful for transfer of genes into mammalian cells in vitro and served as good delivery system composed of biodegradable polymeric materials. Ouchi et al. (1998) have prepared water-soluble poly(ethylene glycol) (PEG)-grafted-chitosan and discussed its aggregation phenomenon in aqueous solutions. Here, the coupling reaction of 6-O-triphenylmethyl-chitosan with methoxy-poly(ethylene glycol) acid was carried out by using EDC in DMF. PEG-grafted-chitosan having a degree of PEG introduction of 25 and $55 \mathrm{~mol} \%$ sugar unit $^{-1}$ were found to form aggregates due to intermolecular hydrogen bonds in aqueous solution. It was also reported that the PEG-grafted-chitosan aggregates could take up a small hydrophobic molecule such as $\mathrm{N}$-phenyl-1-napthylamine. The release rate of $N$-phenyl-1-napthylamine from the aggregates was found to be based on the $\mathrm{pH}$ of the medium. So, the PEG-grafted-chitosan aggregates can be used as a $\mathrm{pH}$ dependant material such as drug carrier.

The drug release behavior of the chitosan-graftedpoly(vinyl alcohol) (PVA) copolymer matrix containing prednisolone was studied under various conditions (Kweon \& Kang, 1999). Due to the increase of PVA grafting percentage from 18.3 to 64.2 apparent release rate constant was slightly decreased from 5.52 to $5.26\left(\mathrm{mg} / \mathrm{cm}^{2}\right.$ day $\left.1 / 2\right)$ at $\mathrm{pH} 1.2$, but increased from 2.99 to $3.82\left(\mathrm{mg} / \mathrm{cm}^{2}\right.$ day $\left.1 / 2\right)$ at $\mathrm{pH}$ 7.4. The drug release behavior of the chitosan-graftedPVA was able to be controlled by the PVA grafting percent, heat treatment, or cross-linking and was also less affected by the $\mathrm{pH}$ values. This result indicates that the chitosan-graftPVA copolymer can be used as a drug carrier. Kim et al. (2002) have prepared the $\mathrm{pH}$-sensitive hydrogels by grafting poly(dimethylsiloxane) (PDMS) onto chitosan using UV irradiation technique. These PDMS substitutions provide the basis for hydrophobic interactions that contribute to the formation of hydrogels. In this work, various graft hydrogels from different weight ratios of chitosan and PDMS (1:1, 1:3, 3:1) have been prepared. These photocrosslinked hydrogels exhibited high equilibrium water content in the range $82-92 \%$. The sample $3: 1$ of the chitosan-PDMS weight ratio showed the highest equilibrium water content in time, temperature and $\mathrm{pH}$-dependant swelling behavior (Fig. 5). Chitosan was modified with polyacrylonitrile through ceric-initiated graft copolymerization (Pourjavadi, Mahdavinia, \& Johuriaan-Mehr, 2003). The chitosan-graft-poly(acrylonitrile) product was then saponified using sodium hydroxide aqueous solution to prepare a novel super adsorbent hydrogel, H-chitosanpolyacrylonitrile. The chitosan-graft-poly(acrylonitrile) and H-chitosan-poly(acrylonitrile) were characterized by FTIR, DSC, TGA and DTG thermal methods. The results showed that both modified chitosans exhibited enhanced thermal 

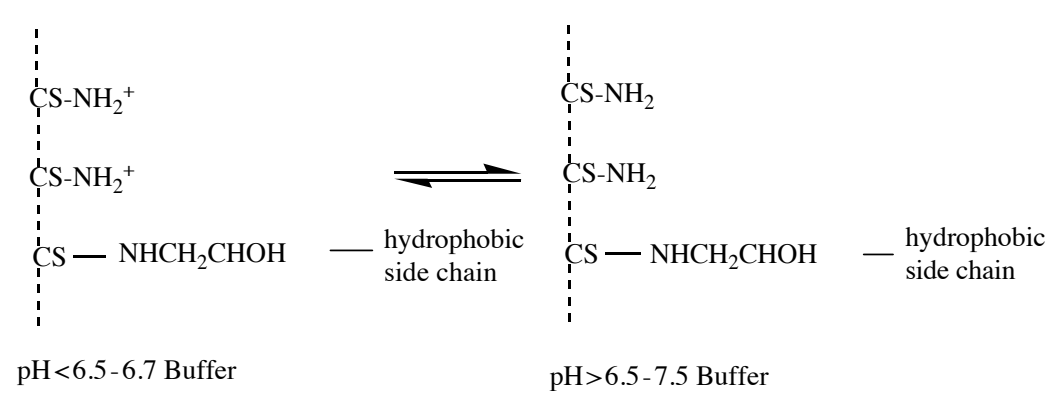

Fig. 5. Structure changes of chitosan grafted copolymer in acidic and alkaline buffer.

stability over chitosan. Swelling capacity of the hydrogel was recognized to affect by alkaline $(\mathrm{NaOH})$ concentration, so that lower concentration of alkaline resulted in higher water absorbency. The super absorbent swelling exhibited a high sensitivity to $\mathrm{pH}$. The study of the net effect of $\mathrm{H}^{+} / \mathrm{OH}^{-}$concentration was carried out at various $\mathrm{pHs}$ in absence of any buffer solution. Sharp and large volume changes were observed as a result of small $\mathrm{pH}$ variations. This super adsorbent polyampholytic network intelligently responding to $\mathrm{pH}$ may be considered as an excellent candidate to design novel drug delivery systems.

\subsection{Tissue engineering}

The present generation of tissue engineering research is based on the seeding of cells onto porous biodegradable polymer matrixes. A primary factor is the availability of good biomaterials to serve as the temporary matrix. These biomaterials must be capable of being prepared in porous forms to offer a channel for the migration of host cells into the matrix permitting growth into complete tissue analogs and be biodegradable into non-toxic products once they have served their function in vivo. The scaffold material has an essential function concerning cell anchorage, proliferation and tissue formation in three dimensions. Performance of these properties demands usually a porous scaffold structure, with the porosity characteristics being application specific. Recently, chitosan and its derivatives have been reported as attractive candidates for scaffolding materials because they degrade as the new tissues are formed, eventually without inflammatory reactions or toxic degradation (Kim, Park, Cho, Chung, Jeong and Lee, 2001; Tuzlakoglu, Alves, Mano, \& Reis, 2004; Baran, Tuzlakoglu, Salgado, \& Reis, 2004).

As a synthetic degradable polymer, with good biocompatible properties, poly-L-lactic acid (PLLA) is widely used in tissue engineering. PLLA has excellent mechanical character; it is used in the fixation of fractured bones in orthopedic and oral surgeries in the form of plates, pins, screws and wires. Also, it can be used as porous 3D scaffolds for bone regeneration. To combine the biological and mechanical properties of chitosan and PLLA, some research works have been reported. Yao, Chen, Wang, Liu, Yao and Sun (2003) have prepared the chitosan-grafted-PLLA for the potential application in tissue engineering. The results showed that the crystallinity of chitosan gradually decreased after grafting, since the side chains substitute the $-\mathrm{NH}_{2}$ groups of chitosan randomly along the chain and destroy the regularity of backing between chitosan chains. The tensile strength of the chitosan-grafted-PLLA copolymers increased along with the enhancement of PLLA/chitosan feed ratio up to 2, after that, the raising of PLLA/chitosan resulted in a decrease of tensile strength. In aqueous solutions, the chitosan-graftedPLLA copolymer was found to be a pH-sensitive hydrogel due to the aggregation of the hydrophobic side chains. The in vitro fibroblast static cultivation on the chitosan-graftPLLA films for 11 days showed that the cell growth rate on the copolymers films was faster than chitosan and decreased when the feed ratio of PLLA to chitosan increases.

A surface functionalization of biodegradable PLLA was achieved by plasma coupling reaction of chitosan with PLLA (Ding, Chen, Gao, Chang, Zhang and Kang, 2004). Contact angle and X-ray photoelectron spectroscopy studies demonstrated that the thickness of the grafted chitosan layer was in the order of several manometers. The proliferation and morphology studies of two cell lines, L-929 (mouse fibroblasts) and L-02 (human hepatocytes), cultured on this surface showed that cells hardly spread and tended to become round, but could proliferate at almost the same speed as cells cultured on glass surface. This insight will help to clarify the mechanism of the switch between cell growth and differentiation. This grafted polymer can be used to control the morphology and function of cells, and has potential applications in tissue engineering. Recently, Kast et al. $(2001,2003)$ demonstrated the biodegradability of thiolated chitosan paving the way for its use as novel scaffold material. In this study, thioglycolic acid was introduced to chitosan via amide bond formation mediated by EDC. Due to the immobilized thiol groups $(240 \mu \mathrm{mol} / \mathrm{g}$ polymer), the viscosity of the polymer increased and formed a transparent gel. Further studies in this direction were performed with L-929 mouse fibroblasts seeded onto chitosan-thioglycolic acid sheets. Results of this study showed that thiolated chitosan can provide a porous scaffold structure guaranteeing cell anchorage, proliferation and tissue formation in three dimensions. Due to the in situ gelling properties it seems possible to provide a certain 


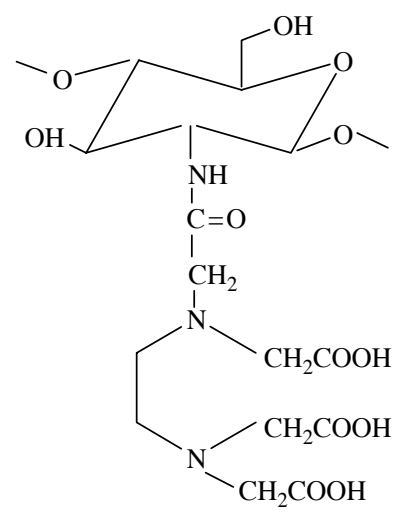

Fig. 6. EDTA-grafted-chitosan.

shape of the scaffold material by pouring a liquid thiolated chitosan cell suspension in a mold. Furthermore, liquid polymer cell suspensions may be applied by injection forming semi-solid scaffolds at the site of tissue damage. Since low concentrated aqueous solutions of thiolated chitosan remain liquid when stored under inert conditions and are rapidly gelling under access of oxygen, they seem to be promising candidates for such applications.

The porous polyglycolide (PGA)-chitosan hybrid matrices are also reported as scaffolds for tissue regeneration (Wang, Lin, Wang, \& Hsieh, 2003). The PGAchitosan hybrid matrices were prepared by using DMSO and acetic acid. The pore structure, mechanical properties and in vitro degradability of these hybrid matrices were altered by varying the weight ratio of PGA. The $75 \%$ PGA hybrid matrix exhibits a high porosity, high strength, good biocompatibility and degradability and is thus a promising biomaterial for tissue engineering applications. The chemical natures of chitosan present in these matrices also enable further chemical modifications, allowing extensive adjustment of the mechanical and biological properties of the matrices.

\subsection{As anti-microbial agents}

Grafted chitosan presents interesting properties for wound-healing applications, because chitosan derivatives can exhibit enhanced bacteriostatic activity with respect to pure chitosan. Ethylene diamine tetraacetic acid (EDTA) grafted onto chitosan (Fig. 6) increases the antibacterial activity of chitosan by complexing magnesium that under normal circumstances stabilizes the outer membrane of gram-negative bacteria (Valanta, Christen, \& Bernkop-Schnurch, 1998). The increase in chitosan antimicrobial activity is also observed with carboxymethyl-chitosan, which makes essential transition metal ions unavailable for bacteria (Muzzarelli, Skjak-Break, Anthonsen, \& Sandford, 1989) or binds to the negatively charged bacterial surface to disturb the cell membrane (Liu, Guan, Yang, Li, \& Yao, 2001). Therefore, the grafted chitosans are used in woundhealing systems, such as carboxymethyl-chitosan for the reduction of periodontal pockets in dentistry (Muzzarelli, Skjak-Break, Anthonsen, \& Sandford, 1989) and chitosan grafted with EDTA as a constituent of hydro- and hydro alcoholic gels for topical use (Valanta, Christen, \& Bernkop-Schnurch, 1998).

A treatment of poly(ethylene terephthalate) (PET) with oxygen plasma glow discharge, followed by a graft copolymerization of acrylic acid (AA), was used to prepare carboxylic acid group introduced PET (PET-AA) (Fig. 7) (Huh, Kang, Lee, Kim, Lee and Park, 2001). Chitosan and quaternized chitosan were then ionically or covalently immobilized on PET-AA. The experiments of antibacterial activity of chitosan-graft-PET against $S$. aureus showed a high growth inhibition in the range of $75-86 \%$ and still maintained a $48-58 \%$ bacterial growth inhibition after laundering. Hu, Jiang, Ding, Ge, Yuan and Yang (2003) also reported the grafting of acrylic acid onto ozone-treated poly (3-hydroxybutyric acid) (PHB) and poly(3-hydroxybutyric acid-co-3-hydroxyvaleric acid) (PHBV) membranes. The resulting membranes were further grafted with chitosan
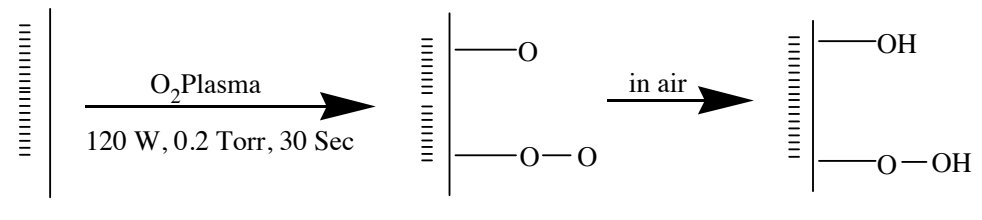

PET

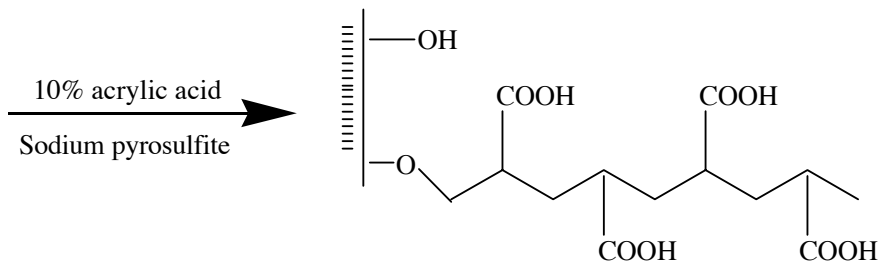

PET-A

Fig. 7. Oxygen plasma treatment of PET and Graft copolymerization of AA on PET. 
or chitooligosaccharide via esterification. These chitosan and chitooligosaccharide grafted membranes showed antibacterial activity against Escherichia coli, Pseudomonas aeruginosa, methicilin-resistant Staphylococcus aureus (MRSA), and S. aureus (Hu et al., 2003). The results showed that the antibacterial activity to MRSA was the lowest among these four bacteria. Acrylic acid grafting increased the biodegradability with Alcaligens faecalis, whereas chitosan and chitooligosaccharide grafting reduced the biodegradability. In addition, chitosan-grafted-PHBV membrane showed higher antibacterial activity and lower biodegradability than chitooligosaccharide grafted membrane.

Two anionic soluble monomers, mono (2-methacryloyl oxyethyl)acid phosphate and vinyl sulfonic acid sodium salt, were grafted onto chitosan to obtain copolymers with zwitterionic property (Jung et al., 1999). It was observed that the grafting reaction improved the antimicrobial activities of chitosan. Also, it was observed that the antimicrobial activity of chitosan and graft copolymers against Candida albicans, Trichophyton rubrum, and Trichophyton violaceum depends largely on the amount and type of grafted chains, as well as on the changes of $\mathrm{pH}$. Yang et al. (2003) prepared polypropylene-graft-acrylic acid using $\gamma$-ray irradiation, and studied its antimicrobial activity. In this study, the chitosan was immobilized onto this material using 1-ethyl-3-(3-dimethyamino propyl) carbodiimide. The antibacterial activity of the polypropylene was enhanced by the modification of $\gamma$-ray radiationinduced grafting of acrylic acid and the immobilization of chitosan onto the polypropylene-graft-acrylic acid modified polymer.

\subsection{Other biomedical applications}

It has been shown (Mao et al., 2004a,b) that chitosan grafted systems have great potential to be used in other biomedical applications, such as in the cardio-vascular field. Mao et al. (2004a; 2004b) studied the blood compatible properties of $O$-butyrylchitosan (OBCS) grafted poly(vinyl chloride) and polyethylene. The surface composition of films and the hydrophilicity on the grafted polymers surface were investigated by ATR-FTIR, ESCA and water contact angle measurements. The blood compatibility of grafted polymers was evaluated with platelet rich plasma. It was found that both poly(vinyl chloride) and polyethylene introduced by OBCS film have good blood compatible properties. The amphiphillic polymers poly(ethylene glycol) (PEG) or poly(ethylene oxide) (PEO), have been used with natural and synthetic macromolecules to obtain hydrophilic biocompatible materials. The surface modification of natural and synthetic macromolecules with watersoluble polymers, such as PEG or PEO can prevent plasma protein adsorption, platelet adhesion, and thrombus formation by steric repulsion mechanism (Ikada, 1984). To improve blood compatibility, chitosan surface has been modified by the complexation-interpenetration method, using an anionic derivative of PEG (Amiji, 1997).

The adhesion and cell growth efficiency of Gly-ArgGly-Asp and $N$-Succinimidyl-6-[4-azido-2-nitophenylamino]-hexanoate grafted chitosan was reported (Chung, Lu, Wang, Lin, \& Chu, 2002). The adhesion and growth of epithelial cells on the grafted chitosans surface have been shown to promote growth rate about $50 \%$ compare to native polymer. The chitosan membrane grafted with hydroxyethyl methacrylate (HEMA) by plasma polymerization was reported ( $\mathrm{Li}$, Liu, \& Fang, 2003). In this work, it was found that water plays an important role in the degree of grafting. The optimum concentration of HEMA in HEMAwater solution is ranges in between 30 and $70 \%$. With increasing plasma time and power the degree of grafting increased to a maximum and then reduced, indicating the coexistence of grafting polymerization and etching of the membrane. The bulk properties of membrane were not significantly changed after modification, although the surface hydrophilicity was improved. It was found that the permeability of chitosan membrane may be controlled through plasma-treatment having potential to be used in dialysis process (Li, Liu, \& Fang, 2003).

\subsection{Adsorption of metal ions}

A great number of chitosan derivatives have been obtained with the aim of adsorbing metal ions by grafting new functional groups on the chitosan backbone. The new functional groups are incorporated with chitosan to increase the density of sorption sites, to change the $\mathrm{pH}$ range for metal sorption and to change the sorption sites in order to increase sorption selectivity for the target metal. In the case of chitosan gel beads, the high water content of the beads leads to poor volumetric density of sorption sites and the grafting of new amine groups may compensate for this drawback: poly(ethyl-enimine) has been successfully grafted on chitosan via different processes using glutaraldehyde (Ruiz, Sastre, \& Guibal, 2002), hexamethylene diisocyanate (Inoue, Baba, \& Yoshizuka, 1993; Sreenivasan, 1998; Tojima, Katsura, Nishiki, Tokura, \& Sakairi, 1999) and epichlorohydrin (Kawamura, Mitsushashi, Tanibe, \& Yoshida, 1993; Juang \& Ju, 1997; 1998). Usually, the sorption behavior of the derivatives follows the same trend as raw chitosan. The acid-base properties of the derivative material may simply shift the optimum $\mathrm{pH}$ range for metal sorption.

The grafting of carboxylic functions has frequently been regarded as an interesting process for increasing the sorption properties of chitosan (Holme \& Hall, 1991). Carboxymethyl chitin and chitosan have been prepared by reaction of chitin/chitosan with chloroacetic acid in propanol as a solvent (Muzzarelli \& Tanfani, 1982; Tokura, Nishimura, \& Nishi, 1983; Muzzarelli, 1988; Tang \& Hon, 2001). Carboxylic acids have also been grafted on chitosan through Schiff's base reactions (Muzzarelli, Tanfani, \& Emanuelli, 
1984, 1985; Muzzarelli, 1985; Muzzarelli \& Zattoni, 1986; Saucedo, Guibal, Roulph, \& Le Cloirec, 1992; Guillen, Sanchez, \& Zamura, 1992, 1994). Usually, the aim of these modifications is to design chelating derivatives for the sorption of metal cations (Muzzarelli \& Tanfani, 1982; Muzzarelli, Tanfani, \& Emanuelli, 1984, 1985; Muzzarelli, 1985; Saucedo, Guibal, Roulph, \& Le Cloirec, 1992). Another way to achieve the grafting of carbonyl and carboxylic functions may consist in reacting chitosan with carboxylic anhydrides (Seo \& Iijima, 1991; Shigemasa, Usui, Morimoto, Saimoto, Okamoto and Minami, 1999). Inoue et al. (1993, 1994, 1995) have developed a number of chitosan derivatives bearing carboxylic and amine groups by grafting EDTA, diethylenetriaminepentaacetic acid (DTPA) (by reaction of the corresponding organic acid anhydride with amine groups of chitosan) and imino diacetic acid (IDA) functions (by reaction of chitosan with glyconitrile, followed by an alkaline hydrolysis reaction) (Inoue, Yamaguchi, Iwaski, Ohto, \& Yoshizuka, 1995; Inoue, Baba, \& Yoshizuka 1993, 1994; Inoue, Ohto, Yoshizuka, Shinbaru, \& Kina, 1995; Nagib, Inoue, Yamaguchi, \& Tamaru, 1999). The reactions are relatively complex and it appears that their use will certainly be limited to the sorption of precious metals. A Schiff's base reaction was used for the grafting of methylpyridine on chitosan in order to prepare a sorbent for precious metal recovery (Baba \& Hirakawa, 1992), and also for copper uptake (Rodrigues, Laranjeira, De Favere, \& Stadler, 1998). Amidoximated composites of chitosan and poly(acrylonitrile) were used for the recovery of metal cations (Kang, Choi, \& Kweon, 1999).

Several phosphorus derivatives of chitosan have also been synthesized (Sakaguchi, Korikoshi, \& Nakajima, 1979; Nishi, Ebina, Nishimura, Tsutsumi, Hasegawa, \& Tokura, 1986, 1987; Choi \& Ahn, 1990) obtained from the reaction of phosphorus pentoxide or phosphorus oxychloride in a suitable solvent (water-free), and by grafting phosphonic acid by the mannich reaction (Heras, Rodriguez, Ramos, \& Agullo, 2001; Ramos, Rodriguez, Rodriguez, Heras, \& Agullo, 2003). Despite the interesting sorption properties of phosphorylated derivatives of chitosan, their use for metal ion sorption is limited due to their poor solubility in water (in most cases) and the affinity of these derivatives for alkaline and alkaline-earth metals. This affinity for these metals may lead to strong competition for the recovery of heavy metals in industrial effluents. Their solubility requires the use of ultra filtration process for the recovery of loaded complexes, or the cross-linking of the soluble product at the expense of possible loss of sorption capacity due to the decrease in the number of available sorption sites.

The grafting of sulphur compounds on chitosan has been the subject of many studies for the design of chelating chitosan-based resins (Ruiz, Sastre, \& Guibal, 2002, 2003, Muzzarelli \& Tanfani, 1982; Ni \& Xu, 1996; Guibal, Vincent, \& Mendoza, 2000; Asakawa, Inoue, Tanaka, \&
Kagaku, 2000; Cardenas, Orlando, \& Edelio, 2001; Guibal, Sweeney, Vincent, \& Tobin, 2002). Different strategies have been used for the preparation of these derivatives, using direct reaction with carbon disulphide to prepare dithiocarbamate chitosan Inoue, Tanaka, \& Kagaku, 2000; Muzzarelli, Tanfani, Gentile, \& Emanuelli, 1982), direct reaction with mercapto acetic acid (Cardenas, Orlando, \& Edelio, 2001), and the grafting of thiourea (or dithiooxamide) via a cross-linking agent such as glutaraldehyde (Guibal, Vincent, \& Mendoza, 2000; Asakawa, Inoue, Tanaka, \& Kagaku, 2000; Cardenas, Orlando, \& Edelio, 2001; Guibal, Sweeney, Vincent, \& Tobin, 2002), or epichlorohydrin, followed by hydrolysis of the intermediary isothiouronium compound) (Monal \& Covas, 1993; Cardenas, Orlando, \& Edelio, 2001). Other sulphur derivatives bearing chloride reactive groups together with sulphur groups (for example chloromethyl thiirane) can also be used (Ni \& Xu, 1996). Becket et al prepared a sulphur derivative by a two step procedure consisting of pre-reaction of chitosan with glutaraldehyde (and reduction by sodium cyanoborohydride) followed by reaction with a mixture of formaldehyde and thioglycolic acid (Becker, Schlaak, \& Strasdeit, 2000). These sulphur derivatives have been successfully tested for the recovery of mercury and the uptake of precious metals, owing to the chelating affinity of sulphur compounds for metal ions. Sulfonic groups have been also grafted on chitosan to improve sorption capacity for metal ions in acidic solutions (Weltrowski, Martel, \& Morcellet, 1996; Kondo, Nakagawa, Matsumoto, Yamashita, \& Furukawa, 1997).

A polyaminated highly porous resin has been prepared from porous beads of chitosan by cross-linking with ethylene glycol diglycidyl ether and then reacting with the cross-linked beads with epichlorohydrin and polyethyleneimine, respectively (Fig. 8) (Kawamura, Mitsushashi, Tanibe, \& Yoshida, 1993). The order of selectivity of adsorption of metal ions onto the resin at $\mathrm{pH} 7$ was $\mathrm{Hg}^{2+}>$ $\mathrm{UO}^{2+}>\mathrm{Cd}^{2+}>\mathrm{Zn}^{2+}>\mathrm{Cu}^{2+}>\mathrm{Ni}^{2+}>\mathrm{Mg}^{2+}$, while $\mathrm{Ca}^{2+}, \mathrm{Ga}^{2+}, \mathrm{As}^{3+}, \mathrm{Sr}^{2+}$ were not observed on the resin at all. The selectivity depended on the $\mathrm{pH}$, with the amount of metal adsorbed decreasing with decreasing $\mathrm{pH}$. The resin was found to have higher adsorption as compared to commercial chelate resin (Kawamura, Mitsushashi, Tanibe, \& Yoshida, 1993). The mechanism of adsorption was shown

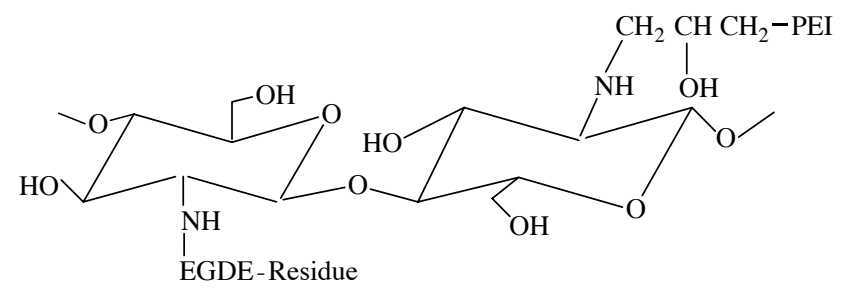

EGDE-ethylene glycol diglycidyl ether PEI-polyethyleneimine

Fig. 8. Chitosan-polyethyleneimine complex. 


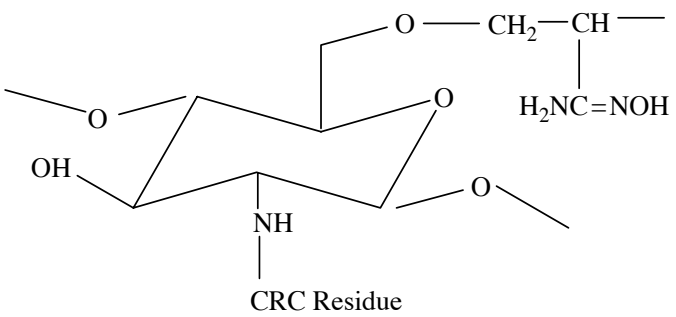

CRC Residue-crosslinked chitosan residue

Fig. 9. Chitosan-grafted-poly(acrylonitrile) (amidoximated).

to be pore diffusion as well as surface diffusion in polyethyleneimine-chitosan particles (Kawamura, Yoshida, Asai, \& Tanibe, 1997). The resin could be effectively reused after repeated cycles of adsorption and elution. Elution of $\mathrm{Hg}$ was effected by sulphuric acid (Kawamura, Yoshida, Asai, \& Tanibe, 1997).

Chitosan grafted with poly(acrylonitrile) has been further modified to yield amidoximated chitosan (Fig. 9) (Kang, Choi, \& Kweon, 1996), a derivative having a higher adsorption for $\mathrm{Cu}^{2+}, \mathrm{Mn}^{2+}$, and $\mathrm{Pb}^{2+}$, compared to crosslinked chitosan. The adsorption capacity had a linear dependence on $\mathrm{pH}$ in cases of $\mathrm{Cu}^{2+}$ and $\mathrm{Pb}^{2+}$. However, a slight decrease in the adsorption capacity was observed in case of $\mathrm{Zn}^{2+}$ and $\mathrm{Cd}^{2+}$ (Kang, Choi, \& Kweon, 1999). Chitosan has been modified with different mono as well as disaccharides. Deoxylactit-1-yl-chitosan could form complexes with $\mathrm{Cu}^{2+}$ and $\mathrm{Fe}^{3+}$ (Chiessi, Palleschi, Paradossi, Venanzi, \& Pispisa, 1991). D-galactose modified chitosan adsorbed rare earth metals as well as base metals and the adsorptivity for trivalent metals was $\mathrm{Ga}^{3+}>\mathrm{In}^{3+}>$ $\mathrm{Nb}^{3+}>\mathrm{Eu}^{3+}$ and for divalent metals it was $\mathrm{Cu}^{2+}>$ $\mathrm{Ni}^{2+}>\mathrm{Co}^{2+}$. The $\mathrm{pH}$ dependency on the distribution ratio was affected by valency of metal ion (Kondo, Sumi, \& Matsumoto, 1996). Thus chitosan with carbohydrate substituents are promising materials for adsorption of metal ions.

$N$-halochitosans prepared by reacting chitosan with sodium hypochlorite are good flocculants for metallic oxides along with many other contaminants (Dingilian \& Heinsohn, 1992). $N$-chloroacetyl chitosan, prepared by reacting chitosan with chloroactic anhydride in chloroacetic acid exhibited high affinity for cations such as $\mathrm{Cu}^{2+}, \mathrm{Fe}^{3+}$ (Mori, Mori, Nishiyama, \& Kurita, 1999). An amino-enone derivative obtained by reacting chitosan with dicarbonyl compounds such as 2, 4-pentane-dione had 38 times higher chelating capacity for $\mathrm{Cu}^{2+}$ and $\mathrm{Co}^{2+}$ than chitosan. This derivative is found to be very stable in the $\mathrm{pH}$ range 3-9 (Guillen, Sanchez, \& Zamora, 1992, 1994). Chitosan derivatives with ketoacids were found to be effective in removal of ${ }^{60} \mathrm{Co}$ from nuclear plant wastewaters as well as the uranium from dilute solutions and from saline waters (Muzzarelli, 1985). It was shown that pyruvic acid modified chitosan had higher adsorption capacities for $\mathrm{Cu}^{2+}, \mathrm{Zn}^{2+}$,

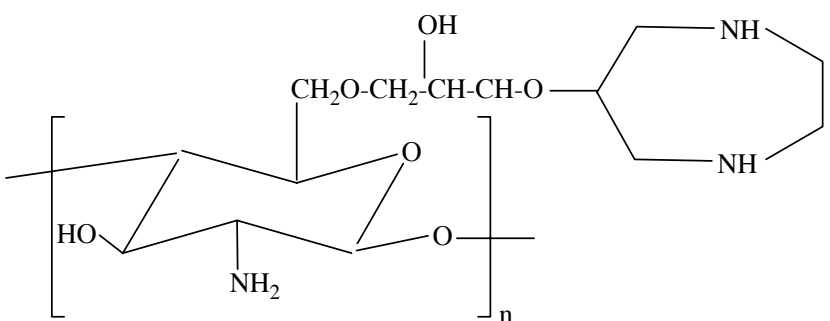

Fig. 10. Mesocyclic diamine-grafted-chitosan crown ether (CTDA).

$\mathrm{Co}^{2+}$ than chitosan and salicylaldehyde modified chitosan (Mu, Zou, \& Gao, 2000).

Recently, a great deal of attention has been paid to the grafting of crown ether on chitosan for manufacturing new metal ion sorbents using a Schiff's base reaction (Peng, Wang, \& Tang, 1998; Tan, Wang, Peng, \& Tang, 1999). Aza crown ether-graft-chitosan and mesocyclic diaminegraft-chitosan crown ether showed high selectivity for $\mathrm{Cu}^{2+}$ in presence of $\mathrm{Pb}^{2+}$ (Yang, Wang, \& Tang, 1999, 2000). $N$-Schiff base type chitosan crown ethers and $\mathrm{N}$ secondary amine type chitosan crown ether showed good adsorption selectivity for $\mathrm{Pd}^{2+}$ in the presence of $\mathrm{Cu}^{2+}$ and $\mathrm{Hg}^{2+}$. Chitosan modified by $3^{\prime}$-allylbenzo15-C-5 and $4^{\prime}$ allylbenzo15-C-5 had good adsorption capacity and selectivity for $\mathrm{Pd}^{2+}$ in the presence of $\mathrm{Cu}^{2+}$ and $\mathrm{Hg}^{2+}$ (Wang, Tan, Peng, Tang, \& Luan, 1999). (Yang \& Yuan, 2001; Yang \& Li, 2002) have reported the static adsorption properties of $\mathrm{Ag}^{+}, \mathrm{Cd}^{2+}, \mathrm{Pb}^{2+}$, and $\mathrm{Cr}^{3+}$ by chitosan hydroxyl azacrown ether (CTS-DA) and chitosan dihydroxyl mesocyclic diamine (CTDA). The results showed that both CTS-DA and CTDA (Fig. 10) has good adsorption capacity and high selectivity for $\mathrm{Ag}^{+}$in the presence of $\mathrm{Pb}^{2+}, \mathrm{Cd}^{2+}$ and $\mathrm{Cr}^{3+}$, and its adsorption selectivity is better than that of chitosan. Yang \& Cheng (2003) have also reported the metal uptake abilities of macrocyclic diamine derivative of chitosan. The polymer has high metal uptake abilities, and the selectivity property for the metal ions was improved by the incorporation of azacrown ether groups in the chitosan. The selectivity for adsorption of metal ions on polymer was found to be $\mathrm{Ag}^{+}>\mathrm{Co}^{2+}>\mathrm{Cr}^{3+}$. These results reveal that the new type chitosan-crown ethers will have wide ranging applications for the separation and concentration of heavy metal ions in environmental analysis.

\subsection{Dyes removal}

Chitosan, due to its high contents of amine and hydroxy functional groups, has an extremely high affinity for many classes of dyes including disperse, direct, reactive, anionic, vat, sulfur and naphthol (Martel, Devassine, Crini, Weltrowski, Bourdonneau, \& Morcellet, 2001); the only class for which chitosan has low affinity is cationic dyes (Chao et al., 2004). The carboxyl groups grafted onto chitosan may serve as electron donors in an alkaline 


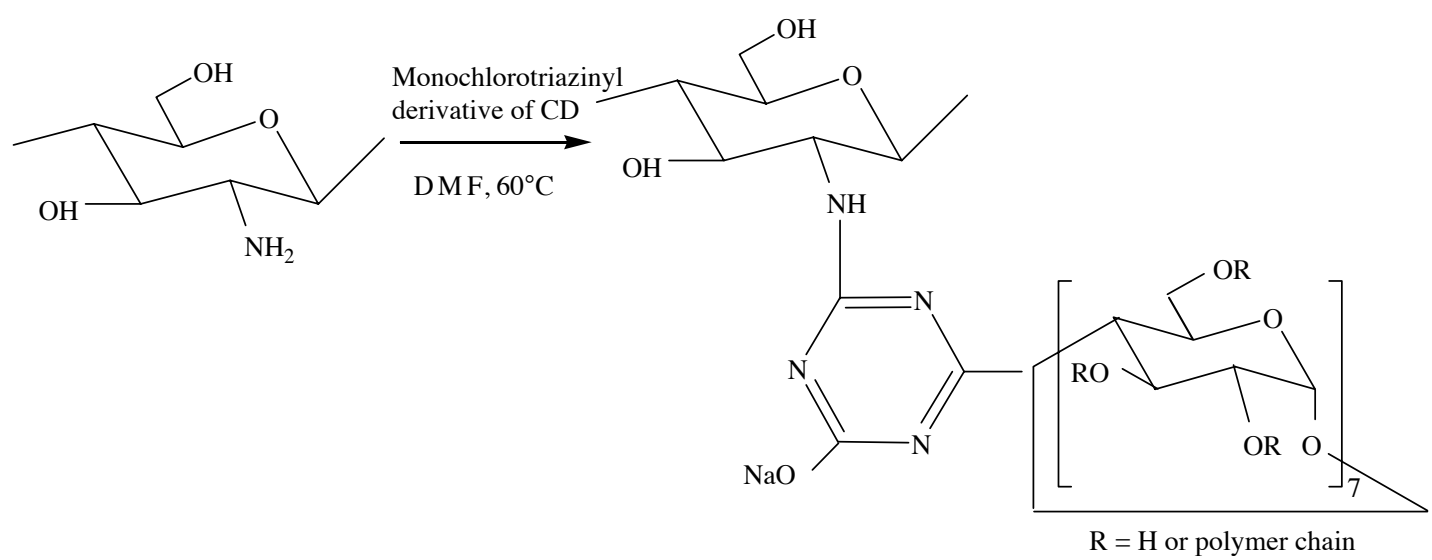

Fig. 11. $\beta$-CD-grafted-chitosan.

environment to confer on chitosan the ability to adsorb cationic dyes from aqueous solutions. Chao et al. (2004) have used four kinds of phenol derivatives such as 4-hydroxybenzoic acid (BA), 3, 4-dihydroxybenzoic acid (DBA), 3, 4-dihydroxyphenyl-actic acid (PA), hydrocaffeic acid (CA) individually as substrates of tyrosinase to graft onto chitosan (CS). The modified chitosan gel beads were found to be effective in adsorption of cationic dyes, such as crystal violet $(\mathrm{CV})$ and Bismarck brown $\mathrm{Y}(\mathrm{BB})$. The adsorption of $\mathrm{CV}$ and $\mathrm{BB}$ by chitosan modified by carboxyl groups is a chemical, equilibrated and saturatable mechanism. After, the enzymatic grafting reaction, the remaining amine groups on these modified chitosans still retained the ability anionic dyes. Langmuir type adsorption was found, and the maximum adsorption capacities for both dyes were increased with the following order: $\mathrm{CS}-\mathrm{CA}>\mathrm{CS}-\mathrm{PA}>\mathrm{CS}-$ DBA $>$ CS-BA.

Cyclodextrin (CD) containing polymers, due to their ability to form host-guest complexes, are compound of interest in many applications; from the stabilization and the controlled release of active components in formulation to extraction and separation processes. The chitosan grafted with $\beta$-CD derivatives have ability to form complexes with a variety of other appropriate compounds, to develop novel sorbent matrices (Tojima, Katsura, Han, Tanida, Nishi and Tokura, 1998; Sreenivasan, 1998; Chen \& Wang, 2001; Aoki, Nishikawa, \& Hattori, 2003). Furusaki et al. (1996) have developed a facile synthesis of a novel chitosan- $\beta-C D$ derivative formed from covalent modification of carboxymethyl- $\beta-C D$ with chitosan having an ability to form an inclusion complex. The property to form an inclusion complex was studied using a fluorescent dye, 6- $(p-$ toluidino)-2-napthalene-6-sulfonate (TNS), as the guest molecule. The polymer guests having free amino groups on the chitosan backbone were found to recognize as TNS molecule through an ionic interaction as well as host-guest complexation. The $\beta-\mathrm{CD}$ was coupled with chitosan by the intermediate of its monochlorotriazinyl derivative (Fig. 11) (Martel, Devassine, Crini, Weltrowski, Bourdonneau, \& Morcellet, 2001). The adsorption of textile dyes from the effluent was carried out with the $\beta$-CD-graft-chitosan derivatives. This study showed that $\beta$-CD-graft-chitosan derivatives have superior rate of sorption and global efficiency than that of parent chitosan polymer and of the well-known cyclodextrin-epichlorohydrin gels. The adsorption behaviors of modified chitosans with higher fatty acid glycidyl toward acid and cationic dyes were examined (Shimizu, Tanigawa, Saito, \& Nakamura, 2005). The adsorption ability of the modified chitosans for anionic dyes at the higher dye concentration was found to be increased with the increase in degree of substitution. The modified chitosans with a lower degree of substitution showed higher adsorption ability than that of an activated carbon at the higher dye concentration. For cationic dyes, the chemically modified chitosan showed a good absorption power.

\section{Conclusions}

Chitosan has the desired properties for safe use in biomedicine, pharmacology and waste water treatment. However, due to its insolubility in neutral and basic aqueous media, its application is restricted. Graft copolymerization is a most attractive technique, which is used to improve chitosan's solubility and widen its applications. Moreover, graft copolymerization is used to attach various functional groups and to control hydrophobic, cationic and anionic properties of grafted chitosan. In this review, we have presented the recent progress on graft copolymerization onto chitosan and its applications. Graft copolymerization onto chitosan is found to be greatly influenced by the type and concentration of initiator, monomer concentration, reaction temperature and time. The properties of grafted polymers have been controlled by the characteristics of the side chains including molecular structure, length, and number. Grafted chitosans have great utility in controlled release and targeting studies of almost all class of bioactive molecules. Recently, grafted chitosans are also extensively explored in tissue engineering for the application in cell 
transplantation and tissue regeneration methodologies. Since chitosan derivatives have enhanced antibacterial activity, they are used in wound-healing management. As a result of the biocompatible properties such as good blood compatibility and cell growth efficiency, grafted chitosan materials have potential to be used in cardio-vascular applications. The high sorption capacities of modified chitosans for metal ions can be of great use for the recovery of valuable metals or the treatment of contaminated effluents. The published literature indicates that grafted chitosans are promising materials namely for biomedical applications. The eventual production and clinical use of such types of implants awaits the take-up of these materials on a more commercial basis that would see the introduction of chitosan based implantable devices.

\section{Acknowledgements}

$\backslash$. Jayakumar thanks the Portuguese Foundation for Science and Technology (FCT) for providing him a Post-Doc scholarship (SFRH/BPD/14670/2003). This work was partially supported by FCT, through the POCTI and/or FEDER programmes and by the European Union funded STREP Project HIPPOCRATES (NMP3-CT-2003-505758).

\section{References}

Ahn, J. S., Choi, H. K., \& Cho, C. S. (2001). Biomaterials, 22(9), 923-928. Alexandrova, V., Obukhova, G. V., Dominina, N. S., \& Topchiev, D. A. (1999). Macromolecular Symposia, 144(2), 413-418.

Amiji, M. M. (1997). Carbohydrate Polymers, 32(3-4), 193-199.

Aoki, N., Nishikawa, M., \& Hattori, K. (2003). Carbohydrate Polymers, 52(3), 219-223.

Artursson, A., Lindmark, T., Davis, S. S., \& Illurn, L. (1994). Pharmaceutical Research, 11, 1358-1361.

Asakawa, T., Inoue, K., Tanaka, T., \& Kagaku, K. (2000). Kogaku Ronbunshu, 26, 321.

Baba, Y., \& Hirakawa, H. (1992). Chemistry Letters, 44, 1905.

Baran, E. T., Tuzlakoglu, K., Salgado, A. J., \& Reis, R. L. (2004). Journal of Material Science, Materials in Medicine, 15(1), 161-165.

Becker, T., Schlaak, M., \& Strasdeit, H. (2000). Reactive and Functional Polymers, 44(3), 289-298.

Berger, J., Reist, M., Mayer, J. M., Belt, O., \& Gurny, R. (2004). European Journal of Pharamaceutics and Biopharmaceutics, 57(1), 35-52.

Berkovich, L. A., Tsyurupa, M. P., \& Davankov, V. A. (1983). Journal of Polymer Science, Part A: Polymer Chemistry Edition, 21(5), 1281-1287.

Bersch, P. C., Nies, B., \& Liebendorfer, A. (1995). Journal of Material Science, Materials in Medicine, 6(2), 231-240.

Blair, H. S., Guthrie, J., Law, T. K., \& Turkington, P. (1987). Journal of Applied Polymer Science, 33(2), 641-656.

Cardenas, G., Orlando, P., \& Edelio, T. (2001). International Journal of Biological Macromolecules, 28(2), 167-174.

Chao, A. C., Shyu, S. S., Lin, Y. C., \& Mi, F. L. (2004). Bioresource Technology, 91(2), 157-162.

Chen, T., Kumar, G., Harris, M. T., Smith, P. J., \& Payne, G. F. (2000). Biotechnology and Bioengineering, 70(5), 564-573.

Chen, S., \& Wang, Y. (2001). Journal of Applied Polymer Science, 82(10), 2414-2421.
Chiessi, E., Palleschi, A., Paradossi, G., Venanzi, M., \& Pispisa, B. (1991). Journal of Chemistry Research and Synthesis, 9(2), 248-255.

Choi, K. S., \& Ahn, H. S. (1990). Polymer Korea, 14(2), 516-520.

Chung, T. W., Lu, Y. F., Wang, S. S., Lin, Y. S., \& Chu, S. H. (2002). Biomaterials, 23(24), 4803-4809.

Ding, Z., Chen, J., Gao, S., Chang, J., Zhang, J., \& Kang, E. T. (2004). Biomaterials, 25(6), 1059-1067.

Dingilian, E. O., \& Heinsohn, G. E. (1992). PCT International Applied, 117, 153112 (WO 9208742. CA).

Don, T. M., King, C. F., \& Chiu, W. Y. (2002). Journal of Applied Polymer Science, 86(12), 3057-3063.

Dordick, J. S. (1992). Trends in Biotechnology, 10(2), 287-293.

Felt, O., Buri, P., \& Gurny, R. (1998). Drug Delivery and Industrial Pharmaceuticals, 24(4), 979-993.

Furusaki, E., Ueno, Y., Sakairi, N., Nishi, N., \& Tokura, S. (1996). Carbohydrate Polymers, 29(1), 29-34.

Guibal, E., Vincent, T., \& Navarro Mendoza, R. (2000). Journal of Applied Polymer Science, 75(1), 119-134.

Guibal, E., Sweeney, N. V. O., Vincent, T., \& Tobin, J. M. (2002). Reactive and Functional Polymers, 50(2), 149-163.

Guibal, E. (2004). Separation and Purification Technology, 38(1), 43-74.

Guillen, M. G., Sanchez, A. G., \& Zamora, M. E. M. (1992). Carbohydrate Research, 233, 255-259.

Guillen, M. G., Sanchez, A. G., \& Zamora, M. E. M. (1994). Carbohydrate Research, 258(1-2), 313-319.

Heras, A., Rodriguez, N. M., \& Ramos, V. M. (2001). Carbohydrate Polymers, 44(1), 1-8.

Hirano, S., Seino, H., Akiyama, I., \& Nonaka, I. (1989). Polymer Engineering Science, 59, 897-901.

Hoffman, A. S., Chen, G., Wu, X., Ding, Z., Kabra, B., Randeri, K., et al. (1997). Polymer Preparations, 38(2), 524-525.

Holme, K. R., \& Hall, L. D. (1991). Canadian Journal of Chemistry, 69(2), $585-590$.

Hu, Y., Jiang, X., Ding, Y., Ge, H., Yuan, Y., \& Yang, C. (2002). Biomaterials, 23(15), 3193-3201.

Hu, S. G., Jou, C. H., \& Yang, M. C. (2003). Journal of Applied Polymer Science, 88(12), 2797-2803.

Huh, M. W., Kang, I. K., Lee, D. H., Kim, W. S., Lee, D. H., \& Park, L. S. (2001). Journal of Applied Polymer Science, 81(11), 2769-2778.

Ikada, Y. (1984). Advances in Polymer Science, 57(1), 103-115.

Illum, L., Farraj, N. F., \& Davis, S. S. (1994). Pharmaceutical Research, 11(6), 1186-1189.

Inoue, K., Baba, Y., \& Yoshizuka, K. (1993). Bulletin of Chemical Society, 66, 2915 (Japan).

Inoue, K., Yoshizuka, K., \& Baba, Y. (1994). In C. Gebelein, \& C. Carraher (Eds.), Biotechnology and Bioactive Polymers (pp. 35-41). New York: Plenum Press.

Inoue, K., Yamaguchi, T., Iwaski, M., Ohto, K., \& Yoshizuka, K. (1995). Separation Science and Technology, 30(12), 2477-2487.

Juang, R. S., \& Ju, C. Y. (1997). Industrial and Engineering Chemistry Research, 36(12), 5403-5409.

Juang, R. S., \& Ju, C. Y. (1998). Industrial and Engineering Chemistry Research, 37(8), 3463-3469.

Jung, B. O., Kim, C. H., Choi, K. S., Lee, Y. M., \& Kim, J. J. (1999). Journal of Applied Polymer Science, 72(13), 1713-1719.

Kang, D. W., Choi, H. R., \& Kweon, D. K. (1996). Pollimo, 20, 989 (CA 126:48548).

Kang, D. W., Choi, H. R., \& Kweon, D. K. (1999). Journal of Applied Polymer Science, 73(4), 469-476.

Kaplan, D. L., Dordick, J. S., Gross, R. A., \& Swift, G. (1998). In R. A. Gross, D. L. Kaplan, \& G. Swift, Enzymes in polymer science: An introduction. Enzymes in polymer synthesis. ACS symposium series (Vol. 684) (pp. 2-16). Washington, DC: American Chemical Society.

Kast, E., Frick, W., Losert, U., \& Schnurch, A. B. (2003). International Journal of Pharmaceutics, 256(1), 183-189.

Kast, E., \& Schnurch, A. B. (2001). Biomaterials, 22(17), 2345-2352. 
Kawamura, Y., Mitsushashi, M., Tanibe, H., \& Yoshida, H. (1993). Industrial and Engineering Chemistry Research, 32(2), 386-391.

Kawamura, Y., Yoshida, H., Asai, S., \& Tanibe, H. (1997). Water Science and Technology, 35(7), 97-105.

Kim, S. Y., Cho, S. M., Lee, Y. M., \& Kim, S. J. (2000). Journal of Applied Polymer Science, 78(7), 1381-1391.

Kim, Y. H., Kim, S. H., \& Park, C. R. (2001). Bioconjugate Chemistry, 12(6), 932-938.

Kim, I. Y., Kim, S. J., Shin, M. S., Lee, Y. M., Shin, D. I., \& Kim, S. I. (2002). Journal of Applied Polymer Science, 85(13), 2661-2666.

Kondo, K., Sumi, H., \& Matsumoto, M. (1996). Separation Science and Technology, 31(8), 1771-1781.

Kondo, K., Nakagawa, S., Matsumoto, M., Yamashita, T., \& Furukawa, I. (1997). Journal of Chemical Engineering, 30(4), 846-852.

Kotze, A. R., Lueßen, H. L., De Leeuw, B. J., De Boer, A. G., Verhoef, J. C., \& Junginger, H. E. (1997). Pharmaceutical Research, 14(9), 1197-1202.

Kumar, G., Smith, P. J., \& Payne, G. F. (1999). Biotechnology and Bioengineering, 63(2), 154-165.

Kumbar, S. G., Soppimath, K. S., \& Aminabhavi, T. M. (2003). Journal of Applied Polymer Science, 87(9), 1525-1536.

Kumbar, S. G., \& Aminabhavi, T. M. (2003). Journal of Applied Polymer Science, 89(11), 2940-2949.

Kurita, K., Kojima, T., Munakata, T., Akao, H., Mori, T., Nishiyama, Y., et al. (1998). Chemistry Letters, 27(4), 317-318.

Kurita, K. (2001). Progress in Polymer Science, 26(9), 1921-1971.

Kweon, D. K., \& Kang, D. W. (1999). Journal of Applied Polymer Science, 74(2), 458-464.

Lagos, A., \& Reyes, J. (1988). Journal of Polymer Science, Part A: Polymer Chemistry Edition, 26(4), 985-991.

Lehr, C. M., Bowstra, J. A., Schacht, E. H., \& Jungiger, H. E. (1992). International Journal of Pharmaceutics, 78(1), 43-48.

Li, Y., Liu, L., \& Fang, F. (2003). Polymer International, 52(2), 285-290.

Liu, X. F., Guan, Y. L., Yang, D. Z., Li, Z., \& Yao, K. D. (2001). Journal of Applied Polymer Science, 79(7), 1324-1335.

Liu, Y., Liu, Z., Zhang, Y., \& Deng, K. (2003). Journal of Applied Polymer Science, 89(8), 2283-2289.

Lueben, H. L., Leeuw, B. J. D., Langemeyer, B. W., Boer, A. G. D., Verhoef, J. C., \& Junginger, H. E. (1996). Pharmaceutical Research, $13,1668-1672$.

Mao, C., Zhao, W. B., Zhu, A. P., Shen, J., \& Lin, S. C. (2004). Material Science \& Engineering-C, 24(4), 479-485.

Mao, C., Zhao, W. B., Zhu, A. P., Shen, J., \& Lin, S. C. (2004). Process Biochemistry, 39(9), 1151-1157.

Martel, B., Devassine, M., Crini, G., Weltrowski, M., Bourdonnaeu, M., \& Morcellet, M. (2001). Journal of Polymer Science, Part-A: Polymer Chemistry Edition, 39(1), 169-176.

Mori, T., Mori, C., Nishiyama, Y., \& Kurita, K. (1999). Kichin, Kitosan, Kenkyu, 5(2), 168-169 (CA 132:139017).

Mu, Q., Zou, Z., \& Gao, Y. (2000). Xiandai Huagong, 20(10), 44-46 (CA.105157).

Muzzarelli, R. A. A., Tanfani, F., Gentile, S., \& Emanuelli, M. (1982). Carbohydrate Research, 104(2), 235-243.

Muzzarelli, R. A. A., Tanfani, F., \& Emanuelli, M. (1984). Carbohydrate Polymers, 4(2), 137-151.

Muzzarelli, R. A. A., Tanfani, F., \& Emanuelli, M. (1985). Biotechnology and Bioengineering, 27(8), 1115-1121.

Muzzarelli, R. A. A., Skjak-Braek, G., Anthonsen, T., \& Sandford, P. (Eds.) . (1989). Elsevier Applied Polymer Science (pp. 87-99). Londres.

Muzzarelli, R. A. A., \& Tanfani, F. (1982). Journal of Macromolecular Science, Part-A: Pure and Applied Chemistry, 54(12), 2141-2151.

Muzzarelli, R. A. A. (1985). Carbohydrate Polymers, 5(2), 85-89.

Muzzarelli, R. A. A. (1986). Chitin in nature and technology. New York: Plenum press.

Muzzarelli, R. A. A. (1988). Carbohydrate Polymers, 8(1), 1-21.

Muzzarelli, R. A. A. (1997). Cell Molecular and Life Science, 53(1), $131-140$.
Muzzarelli, C., \& Muzzarelli, R. A. A. (2002). Trends in Glycoscience and Glycotechnology, 14, 223-229.

Nagib, S., Inoue, K., Yamaguchi, T., \& Tamaru, T. (1999). Hydrometallurgy, 51(1), 73-85.

Najjir, A. M. K., Yunus, W. M. Z. W., Ahmad, M. B., \& Rahman, M. Z. A. B. (2000). Journal of Applied Polymer Science, 77(10), 2314-2318.

Ng, L. T., Guthrie, J. T., Juan, Y. J., \& Zhao, H. (2001). Journal of Applied Polymer Science, 79(3), 466-472.

Ni, C., \& Xu, Y. (1996). Journal of Applied Polymer Science, 59(3), 499-504

Nishi, N., Ebina, A., Nishimura, S. I., Tsutsumi, A., Hasegawa, O., \& Tokura, S. (1986). International Journal of Biological Macromolecules, 8(5), 311-317.

Nishi, N., Ebina, A., Nishimura, S. I., Tsutsumi, A., Hasegawa, O., \& Tokura, S. (1987). International Journal of Biological Macromolecules, 9(2), 109-114.

Ono, K., Saito, Y., Yura, H., \& Ishikawa, K. (2000). Journal of Biomedical Material Research, 49(2), 289-295.

Ouchi, T., Nishizawa, H., \& Ohya, Y. (1998). Polymer, 39(21), 5171-5175.

Pedram, M. Y., Lagos, A., Campos, N., \& Retuert, J. (1992). International Journal of Polymeric Materials, 18(1), 25-30.

Pedram, M. Y., Lagos, A., Retuert, J., Guerrero, R., \& Riquelme, P. (1995). Journal of Macromolecular Science, Part. A: Pure \& Applied Chemistry, A32(5), 1037-1047.

Pedram, M. Y., Retuert, J., \& Quijada, R. (2000). Macromolecular Chemistry and Physics, 201(4), 923-930.

Pedram, M. Y., \& Retuert, J. (1996). Journal of Applied Polymer Science, 63(10), 1321-1326

Peng, C., Wang, Y., \& Tang, Y. (1998). Journal of Applied Polymer Science, 70(3), 501-506.

Pengfei, L., Maolin, Z., \& Jilan, W. (2001). Radiation Physics and Chemistry, 61(1), 149-153.

Pourjavadi, A., Mahdavina, G. R., Mehr, M. J. Z., \& Omidian, H. (2003). Journal of Applied Polymer Science, 88(8), 2048-2054.

Pourjavadi, A., Mahdavinia, G. R., \& Johuriaan, M. M. J. (2003). Journal of Applied Polymer Science, 90(11), 3115-3121.

Prabaharan, M., \& Mano, J. F. (2005). Drug Delivery, 12(1), 41-57.

Prasanth, K. V. H., \& Tharanathan, R. N. (2003). Carbohydrate Polymers, 54(3), 343-351.

Radhakumary, C., Divya, G., Nair, P. D., Mathew, S., \& Nair, C. P. R. (2003). Journal of Macromolecular Science, Pure and Applied Chemistry, 40(7), 715-730.

Ramos, V. M., Rodriguez, N. M., Rodriguez, M. S., Heras, A., \& Agullo, E. (2003). Carbohydrate Polymers, 51(4), 425-429.

Ravi Kumar, M. N. V., Muzzarelli, R. A. A., Muzzarelli, C., Sashiwa, H., \& Domb, A. J. (2004). Chemical Reviews, 104(12), 6017-6084.

Ravi kumar, M. N. V. (2000). Reactive and Functional Polymers, 46(1), $1-27$.

Retuert, J., \& Yazdani, P. M. (1993). Polymer Bulletin (Berlin), 31(3), $559-565$.

Rodrigues, C. A., Laranjeira, M. C. M., De Favere, V. T., \& Stadler, E. (1998). Polymer, 39(21), 5121-5126.

Ruiz, M., Sastre, A. M., \& Guibal, E. (2002). Separation Science and Technology, 37(10), 2385-2403.

Ruiz, M., Sastre, A. M., \& Guibal, E. (2003). Solvent Extraction and Ion Exchange, 21(2), 307-329.

Sakaguchi, T., Korikoshi, T., \& Nakajima, A. (1979). Nippon Nogeigaku Kaishi, 53, 149

Sanford, P. A. (1989). In G. Skjak-Braek, T. Anthonsen, \& P. A. Sanford (Eds.), Chitin and chitosan-sources, chemistry, biochemistry, physical properties and applications (pp. 51-70). London: Elsevier.

Sashiwa, H., \& Shigemasa, Y. (1999). Carbohydrate Polymers, 39(2), $127-138$.

Saucedo, I., Guibal, E., Roulph, C., \& Le Cloirec, P. (1992). Environmental Technology, 13(12), 1101-1116. 
Senel, S., \& McClure, S. J. (2004). Advanced Drug Delivery Reviews, 56(10), 1467-1480.

Seo, T., \& Iijima, T. (1991). In C. G. Gebelein (Ed.), Biotechnology and Polymers (pp. 215-227). New York, NY: Plenum press.

Shantha, K. L., Bala, U., \& Rao, K. P. (1995). European Polymer Journal, 31(4), 377-382.

Shanthi, C., \& Rao, K. P. (2001). Carbohydrate Polymers, 44(2), 123-131.

Shigemasa, Y., Usui, H., Morimoto, M., Saimoto, H., Okamoto, Y., Minami, S., et al. (1999). Carbohydrate Polymers, 39(3), 237-243.

Shigeno, Y., Kondo, K., \& Takemoto, K. (1982). Journal of Macromolecular Science, Pure and Applied Chemistry, A17(4), 571-583.

Shimizu, Y., Tanigawa, S., Saito, Y., \& Nakamura, T. (2005). Journal of Applied Polymer Science, 96(6), 2423-2428.

Singh, V., Tripathi, D. N., Tiwari, A., \& Sanghi, R. (2005). Journal of Applied Polymer Science, 95(4), 820-825.

Singh, D. K., \& Roy, A. R. (1997). Journal of Applied Polymer Science, 66(5), 869-877.

Singh, D. K., \& Ray, A. R. (1998). Carbohydrate Polymers, 36(2-3), 251-255.

Sreenivasan, K. (1998). Journal of Applied Polymer Science, 69(6), $1051-1055$

Sridhari, T. R., \& Dutta, P. K. (2000). Indian Journal of Chemical Technology, 7(1), 198-204.

Sugimoto, M., Morimoto, M., \& Sashiwa, H. (1998). Carbohydrate Polymers, 36(1), 49-59.

Suh, J. K. F., \& Matthew, H. W. T. (2000). Biomaterials, 21(24), 2589-2598.

Sun, T., Xu, P., Liu, Q., Xue, J., \& Xie, W. (2003). European Polymer Journal, 39(1), 189-192.

Sun, T., Xie, W., \& Xu, P. (2004). Carbohydrate Polymers, 58(4), 379-382.

Tahlawy, K. E. L., \& Hudson, S. M. (2001). Journal of Applied Polymer Science, 82(3), 683-702.

Tan, S., Wang, Y., Peng, C., \& Tang, Y. (1999). Journal of Applied Polymer Science, 71(12), 2069-2074.

Tang, L. G., \& Hon, D. N. S. (2001). Journal of Applied Polymer Science, 79(12), 1476-1485.

Tasker, R. A., Connell, B. J., Ross, S. J., \& Elson, C. M. (1998). Laboratory Animals, 32(2), 270-275.

Terada, N., Morimoto, M., Saimoto, H., Okamato, Y., Minami, S., \& Shigemasa, Y. (1999). Chemistry Letters, 28(12), 1285-1286.

Thanou, M., Verhoef, J. C., \& Junginger, H. E. (2001). Advanced Drug Delivery Reviews, 52(2), 117-126.

Tojima, T., Katsura, H., Han, S. M., Tanida, F., Nishi, N., \& Tokura, S. (1998). Journal of Polymer Science, Part-A: Polymer Chemistry Edition, 36(11), 1965-1968.

Tojima, T., Katsura, H., Nishiki, M., Tokura, S., \& Sakairi, N. (1999). Carbohydrate Polymers, 40(1), 17-22.
Tokura, S., Nishimura, S. I., \& Nishi, N. (1983). Polymer Journal, 15(3), 597-603.

Tuzlakoglu, K., Alves, C. M., Mano, J. F., \& Reis, R. L. (2004). Macromolecular Bioscience, 4(8), 811-819.

Vachoud, L., Chen, T., Payne, G. F., \& Duhalt, R. V. (2001). Enzyme and Microbial Technology, 29(6-7), 380-385.

Valanta, C., Christen, B., \& Bernkop-Schnurch, A. (1998). Journal of Pharmacy and Pharmacology, 50(2), 445-452.

Verma, A. J., Deshpande, S. V., \& Kennedy, J. K. (2004). Carbohydrate Polymers, 55(1), 77-93.

Wang, Y., Tan, S., Peng, C., Tang, Y., \& Luan, Z. (1999). Huanjing Kexue, 20(4), 55-58 (CA 133:231961).

Wang, Y. C., Lin, M. C., Wang, D. M., \& Hsieh, H. J. (2003). Biomaterials, 24(6), 1047-1057.

Weltrowski, M., Martel, B., \& Morcellet, M. (1996). Journal of Applied Polymer Science, 59(4), 647-654.

Xie, W. M., Xu, P. X., Wang, W., \& Lu, Q. (2001). Bioorganic \& Medicine Chemical Letters, 11, 1699.

Xie, W., Xu, P. X., Liu, Q., \& Xue, J. (2002). Polymer Bulletin, 49(1), $47-54$.

Xie, W. M., Xu, P. X., Wang, W., \& Lu, Q. (2002). Carbohydrate Polymers, 50(1), 35-40.

Yalpani, M., Marchessault, R. H., Morin, F. G., \& Monasterious, C. J. (1991). Macromolecules, 24(22), 6046-6049.

Yamada, K., Chen, T., Kumar, G., Vesnovsky, O., Topoleski, L. T. D., \& Payne, G. F. (2000). Biomacromolecules, 1(2), 252-258.

Yang, S., Tirmizi, S. A., Burns, A., Barney, A. A., \& Risen, W. M. (1989). Synthetic Metals, 32(2), 191-200.

Yang, Z., Wang, Y., \& Tang, Y. (1999). Journal of Applied Polymer Science, 74(13), 3053-3058.

Yang, J. M., Lin, H. T., Wu, T. H., \& Chen, C. C. (2003). Journal of Applied Polymer Science, 90(15), 1331-1336.

Yang, Z. K., \& Yuan, Y. (2001). Journal of Applied Polymer Science, 82(8), 1838-1843.

Yang, Z., \& Li, J. (2002). Journal of Applied Polymer Science, 86(11), $2677-2681$.

Yang, Z., \& Cheng, S. (2003). Journal of Applied Polymer Science, 89(4), 924-929.

Yao, F., Chen, W., Wang, H., Liu, H., Yao, K., Sun, P., et al. (2003). Polymer, 44(21), 6435-6441.

Yilmaz, Y., Caner, H., Hasipoglu, H., \& Yilmaz, O. (1998). European Polymer Journal, 34(3-4), 493-497.

Yoshikawa, S., Takayama, T., \& Tsubokawa, N. (1998). Journal of Applied Polymer Science, 68(11), 1883-1889.

Yu, L., He, Y., Bin, L., \& Yuée, F. (2003). Journal of Applied Polymer Science, 90(10), 2855-2860.

Zhang, J., Yuan, Y., Shen, J., \& Lin, S. (2003). European Polymer Journal, 39(4), 847-850. 